\title{
Microstructural and Chemical Constitution of the Oxide Scale formed on a Pesting-Resistant Mo-Si-Ti Alloy
}

\author{
Susanne Obert ${ }^{1}$, Alexander Kauffmann ${ }^{1 *}$, Sascha Seils ${ }^{1,2}$, Torben Boll ${ }^{1,2}$, Sandra \\ Kauffmann-Weiss ${ }^{3}$, Hans Chen ${ }^{4}$, Ronja Anton ${ }^{5}$ and Martin Heilmaier ${ }^{1}$ \\ ${ }^{1}$ Karlsruhe Institute of Technology (KIT), Institute for Applied Materials (IAM-WK), Engelbert- \\ Arnold-Straße 4, 76131 Karlsruhe, Germany \\ ${ }^{2}$ Karlsruhe Nano Micro Facility (KNMF), Karlsruhe Institute of Technology (KIT), Hermann-von- \\ Helmholtz-Platz 1, 76344, Eggenstein-Leopoldshafen, Germany \\ ${ }^{3}$ Karlsruhe Institute of Technology (KIT), Innovation Campus Future Mobility (ICM), Kaiserstraße \\ 12, 76131 Karlsruhe, Germany \\ ${ }^{4}$ Karlsruhe Institute of Technology (KIT), Institute for Technical Physics (ITEP), Hermann-von- \\ Helmholtz-Platz 1, 76344 Eggenstein-Leopoldshafen, Germany \\ ${ }^{5}$ German Aerospace Center (DLR), Institute of Materials Research, Linder Hoehe, 51147 Köln, \\ Germany \\ * corr. author: alexander.kauffmann@ kit.edu; +49 72160842346
}

\begin{abstract}
1 The oxidation behaviour of the pesting-resistant eutectic alloy Mo-20Si-52.8Ti was investigated by 2 addressing the microstructural and chemical constitution by grazing incidence X-ray diffraction GIXRD 3 and atom probe tomography APT of oxide scales formed at 800 and $1200{ }^{\circ} \mathrm{C}$ in order to understand their protective character. The duplex Si-Ti-oxide scale formed at $800{ }^{\circ} \mathrm{C}$ in air, i.e. within the so-called "pesting regime", is considerably slow growing with a scale thickness of $(11 \pm 3) \mu \mathrm{m}$ after $1000 \mathrm{~h}$ of exposure. It is composed of a $\mathrm{Ti}(+\mathrm{IV})$-oxide with the chemical composition of approximately $\mathrm{TiO}_{2.1}$ confirmed by APT and $\mathrm{SiO}_{2}$ islands, which are most likely amorphous. The oxide scale formed at $1200{ }^{\circ} \mathrm{C}$, a potential application temperature, is characterised by a top single-phase scale and an underlying duplex scale with a considerably increased thickness of $(68 \pm 11) \mu \mathrm{m}$ in total. It consists of rutile $\mathrm{TiO}_{2}$ and some cristobalite $\mathrm{SiO}_{2}$ as determined by GIXRD. APT analysis of the top Ti-oxide scale confirms the stoichiometry $\mathrm{TiO}_{2.2}$. The underlying duplex scale comprising $\mathrm{Ti}$ - and $\mathrm{Si}$-oxide is characterised by strongly off-stoichiometric compounds, namely $\mathrm{TiO}_{1.4}$ and $\mathrm{SiO}_{1.6}$. Initial linear oxide scale growth kinetics are found at $800{ }^{\circ} \mathrm{C}$, which change to cubic kinetics for exposure times longer than $100 \mathrm{~h}$. At higher temperatures of 1100 and $1200{ }^{\circ} \mathrm{C}$, diffusion-controlled, almost parabolic kinetics prevail.
\end{abstract}

\section{Keywords}




\section{Introduction}

The development of Mo-Si-based alloys for high-temperature applications as potential alternatives to state-of-the-art Ni-based superalloys is challenged by a judicious combination of sufficient creep resistance with adequate oxidation resistance. At elevated temperatures, this oxidation resistance can be achieved by: (i) Micro-alloying with B leads to a decrease in oxide scale viscosity [1] enabling quick coverage of the substrate surface by a borosilicate layer retarding further $\mathrm{O}$ ingress [2-4]. (ii) $\mathrm{M}_{5} \mathrm{Si}_{3}$ silicides with a higher $\mathrm{Si}$ content compared to $\mathrm{M}_{3} \mathrm{Si}$ silicides (with $\mathrm{M}$ representing $\mathrm{Mo}$ or $\mathrm{Ti}$, respectively) can be stabilised [5], which facilitate formation of a $\mathrm{SiO}_{2}$ oxide scale [6]. However at temperatures below $1000{ }^{\circ} \mathrm{C}$, catastrophic oxidation is characteristic for all Mo-Si-based alloys since the kinetics of $\mathrm{SiO}_{2}$ formation is too slow in order to outbalance the formation of volatile $\mathrm{MoO}_{3}$ leading to rapid mass loss [7, 8], called "pesting". Among multiple alloy design approaches, the ternary Mo-SiTi alloys were found to be the most promising regarding suppression of pesting [9]. A fully eutectic Mo20Si-52.8Ti (at\%) alloy possessing a two-phase, fine-scaled microstructure of Mo solid solution Moss and $(\mathrm{Ti}, \mathrm{Mo})_{5} \mathrm{Si}_{3}$ was found not to undergo catastrophic oxidation at $800{ }^{\circ} \mathrm{C}$ [9]. An excellent oxidation resistance was observed with negligible specific mass changes in the order of $2 \mathrm{mg} / \mathrm{cm}^{2}$ (isothermal) and $0.3 \mathrm{mg} / \mathrm{cm}^{2}$ (cyclic) at $800{ }^{\circ} \mathrm{C}$ after $100 \mathrm{~h} \mathrm{[9].} \mathrm{This} \mathrm{unexpected,} \mathrm{outstanding} \mathrm{oxidation} \mathrm{behaviour} \mathrm{has}$ been attributed to the formation of a mixed $\mathrm{SiO}_{2}-\mathrm{TiO}_{2}$ layer with a scale thickness of less than $10 \mu \mathrm{m}$ [9]. These observations were in striking contrast to the eutectoid Mo-Si-Ti alloy Mo-21Si-34Ti, being composed of Moss and (Mo,Ti) $)_{5} \mathrm{Si}_{3}$, which suffered from severe pesting [9].

To summarise, our previous studies focused on the chemical and microstructural conditions for achieving pesting-resistance in eutectic-eutectoid Mo-Si-Ti alloys. It turned out that a threshold in nominal Ti content of minimum 43 at $\%$ is mandatory in order to obtain adequate oxidation resistance in the pesting regime $[10,11]$. Moreover, it was found that the fine length scale of the eutectic microstructure is not required in order to achieve pesting-resistance since a considerably, artificially coarsened eutectic alloy exhibited a similarly good oxidation behaviour [11]. Thus, the chemical composition of the individual phases proved to be decisive whether pesting could be suppressed or not. While both $\mathrm{M}_{5} \mathrm{Si}_{3}$ silicides (with " $\mathrm{M}$ " being either Ti or Mo or a combination of both), hexagonal $(\mathrm{Ti}, \mathrm{Mo})_{5} \mathrm{Si}_{3}$ and tetragonal $(\mathrm{Mo}, \mathrm{Ti})_{5} \mathrm{Si}_{3}$, exhibit an adequate oxidation resistance in the pesting regime $[12,13]$, it is the pesting-critical Moss phase which is responsible for the dominance of $\mathrm{MoO}_{3}$ evaporation [11]. Continuous pathways of the Ti-oxide are present in the duplex scale connecting the alloy substrate with the outer $\mathrm{TiO}_{2}$ oxide scale among all investigated Mo-Si-Ti alloys [10]. This is surprising with regard to the anticipated minor oxidation resistance of $\mathrm{TiO}_{2}$, which is well known to exhibit scale cracking and spallation [14-17].

In conclusion, the reasons for the passivating character of the mixed Si-Ti-oxide scale formed on the eutectic alloy at 800 and $1200{ }^{\circ} \mathrm{C}$, and especially the non-detrimental character of Ti-oxide still remain unclear. Therefore, this article addresses the crystallographic and chemical appearance of the oxide 
scales and their growth characteristics. In particular, focus is placed on the solubility of the species $\mathrm{Si}$, $\mathrm{Ti}$ and Mo in the oxide phases by means of atom probe tomography (APT), in order to analyse its impact on the pesting stability.

\section{Experimental}

The alloys were manufactured by repetitive arc-melting of the bulk high-purity elements Mo, $\mathrm{Si}$ and $\mathrm{Ti}$ with purities of $99.95,99.99$ and $99.8 \%$, respectively. Therefore, an AM/0,5 device provided by Edmund Bühler equipped with a button-shaped, water-cooled $\mathrm{Cu}$ crucible was used. Subsequent to multiple evacuating ( $<2 \times 10^{-4}$ mbar) and Ar-flooding steps, a final Ar atmosphere of 600 mbar was established, which was further cleaned from $\mathrm{O}$ residuals by pre-melting a $\mathrm{Zr}$ lump. Repetitive melting (min. five times) ensured a homogenous element distribution. The resulting composition was confirmed to vary less than $0.5 \mathrm{wt} \%$ from the initial nominal composition by inductively coupled plasma optical emission spectroscopy.

Cyclic oxidation experiments were performed on samples with dimensions of $(5 \times 5 \times 4) \mathrm{mm}^{3}$ and a surface finish of SiC grit P2500. Oxidation testing was conducted at laboratory air in muffle furnaces by Carbolite Gero and Nabertherm at 800 and $1200{ }^{\circ} \mathrm{C}$ for a test duration in total of 1000 and $100 \mathrm{~h}$, respectively, with cycle durations varying between 1 to $10 \mathrm{~h}$. The samples were cooled down to room temperature between each cycle and their mass change was recorded by means of a balance (Sartorius precision of $\pm 1 \mu \mathrm{g}$ ). The samples were maintained in $\mathrm{Al}_{2} \mathrm{O}_{3}$ crucibles during testing, but turned around after each cycle to allow uniform oxidation of all surfaces.

The cross sections of the oxidation samples were analysed by scanning electron microscopy (SEM) after representative oxidation durations. Therefore, the oxidation samples were cold mounted and prepared by grinding steps down to SiC grit P2500 and subsequent polishing with 3 and $1 \mu \mathrm{m}$ diamond suspension and finally with stabilised silica suspension provided by Struers. A LEO EVO 50 SEM by Zeiss was used at an acceleration voltage of $20 \mathrm{kV}$. Backscattered electron (BSE) imaging contrast, providing atomic number and thus material contrast, allowed the characterisation of the oxide scale morphology. The used SEM was equipped with an energy dispersive X-ray spectroscopy (EDX) system, which allowed for an estimation of the chemical composition of the phases within the substrate. Quantitative evaluation of the oxide scale thickness and the areal fractions of the respective oxides was performed by applying image processing techniques, based on thresholding greyscale values and pixel connectivity analysis using the software ImageJ and a self-written Matlab script.

In order to investigate the crystal structure of the formed oxide scales, grazing incidence X-ray diffraction (GIXRD) analyses were performed. Therefore, a Rigaku SmartLab diffractometer was used, equipped with a HyPix-3000 detector in 0D mode and a $\mathrm{Cu} \mathrm{K} \alpha$ radiation source. The sample was aligned by the usage of an Rx/Ry stage. The measurements were performed with a parallel beam and a $5^{\circ}$ soller slit in the primary beam path at incident angles $\omega$ varying between 1.2 and $2.5^{\circ}$. 
Further analysis of the elemental distribution within the oxide scales was performed by means of 3D atom probe tomography (APT). The tips from the oxide layers were prepared in a Strata dual beam SEM/focused ion beam device by FEI. Firstly, the regions of interest were protected by a Pt layer to avoid damage caused by the $\mathrm{Ga}^{+}$ion beam. Parts of an originally $(25 \times 4 \times 3) \mu \mathrm{m}^{3}$ sized rod were set to Si micro-posts provided by Cameca. Next, tips were shaped by annular milling at $30 \mathrm{kV}$ with decreasing inner diameter down to $0.2 \mu \mathrm{m}$. Final milling with a closed circular pattern was performed at $5 \mathrm{kV}$ acceleration voltage to minimize the $\mathrm{Ga}^{+}$affected layer at the surface.

Atom probe analyses were conducted in a LEAP 4000X HR by Cameca. The device was operated in laser mode (UV laser with $\lambda=355 \mathrm{~nm}$ ) at a pulse energy of 50 or $100 \mathrm{pJ}$ and a pulse repetition rate of 100 or $125 \mathrm{kHz}$. The temperature was set to $50 \mathrm{~K}$ and the standing high voltage was controlled according to a detection rate of 0.3 to $0.5 \%$.

Atom probe data were reconstructed and analysed by the IVAS 3.6.14 software by Cameca. The chemical composition was determined using the peak deconvolution analysis to take the possible overlap of peaks into account, especially, the overlap of $\mathrm{TiO}^{2+}$ and $\mathrm{O}_{2}{ }^{+}$at $32 \mathrm{Da}$. Furthermore, APT analyses of oxides, as well as carbides and nitrides, have shown that the quantification of the chemical composition may depend on the experimental conditions [18-21]. An underestimation of the $\mathrm{O}$ content could be caused by preferential co-evaporation of $\mathrm{O}$ or $\mathrm{O}$-containing ions during the same laser pulse leading to multiple signals on the detector, which cannot be separated [20]. Hence, a critical discussion of the obtained compositions is necessary. It can be assumed that a possible $\mathrm{O}$ underestimation is consistent for experimental conditions not varying substantially. These conditions are strongly influenced by the evaporation field which depends on, e.g. the pulse energy, tip radius and material. Varying evaporation fields can lead to significant changes in (i) the fraction of pulses leading to multiple signals and/or (ii) the ratio of detected ions of the same species with different charge. The tips discussed in this article exhibit about $80 \%$ single signals and comparable ratios of ions at different charge states. Hence, similar experimental conditions can be assumed for the APT investigations. Additionally, it was guaranteed that no significant co-evaporation of $\mathrm{O}$ ions occurred during laser pulses. Therefore, a self-written software by Boll et al. [22] was used to create separate mass spectra containing ions from single signals or multiple signals, respectively. It was found that (i) the overall $\mathrm{O}$ content in the mass spectra derived from multiple signals was lower than that from single signals and (ii) no disproportionally high amount of $\mathrm{O}$ or $\mathrm{O}_{2}$ ions occurred. Hence, it is unlikely that the APT analysis conditions cause a significant $\mathrm{O}$ underestimation in the APT results.

The coefficient of thermal expansion (CTE) was determined by an optical dilatometer heating microscope by LINSEIS. Here, the sample was compared to an $\mathrm{Al}_{2} \mathrm{O}_{3}$ reference during measurement. The length difference was detected by a CCD camera. The CTE was analysed with a heating rate of $10{ }^{\circ} \mathrm{C} / \mathrm{min}$ over the temperature range from 300 to $1200{ }^{\circ} \mathrm{C}$ under Ar flow of $3 \mathrm{sccm} / \mathrm{min}$. 


\section{Results and discussion}

In the following paragraphs we present structural (Sect. 3.1) and chemical investigations (Sect. 3.2) of the oxide scales formed on the eutectic Mo-20Si-52.8Ti alloy (at\%) at 800 and $1200{ }^{\circ} \mathrm{C}$. Thereafter, oxide scale growth kinetics will be evaluated in order to assess the rate-controlling processes (Sect. 3.3). In contrast to our previous article [10], where the distribution of the solid and volatile oxide forming species Ti, Si and Mo within the (sub-)oxide scales was evaluated, the evolution of the oxide scale thickness with time at different temperatures is focused on. In the following, oxides, in which Ti cations represent the major cationic component, are referred to as Ti-oxide, whereas oxides possessing majority $\mathrm{Si}$ cations as metal ions will be designated as Si-oxide. These terms are only meant as general, qualitatively distinction and are not to be misinterpreted by oxidation levels, or stoichiometry relations. These will be named and discussed where they are of particular interest (Sect. 3.2).

\subsection{Structural characterisation of the oxide scales formed at 800 and $1200{ }^{\circ} \mathrm{C}$}

The general oxidation behaviour of the eutectic Mo-20Si-52.8Ti alloy has been studied in detail in Refs. $[9,11]$ for the as-cast and homogenised heat-treated condition with no significant differences in oxide scale formation and oxidation behaviour observed. Thus, we now focus on the detailed investigation and understanding of the formed oxide scales of the as-cast (ac) condition. The two-phase eutectic microstructure is differently fine-scaled and textured depending on the temperature profile during cooling after arc melting, and thus also partially degenerated (see Fig. 1: Moss white and (Ti,Mo) ${ }_{5} \mathrm{Si}_{3}$ bright grey in BSE contrast). After being cyclically exposed to air at $800{ }^{\circ} \mathrm{C}$ for $100 \mathrm{~h}$ a thin duplex oxide scale of approximate $(5 \pm 2) \mu \mathrm{m}$ in thickness is formed (see Fig. 1b), which grows to a thickness of $(11 \pm 3) \mu \mathrm{m}$ after $1000 \mathrm{~h}$ of oxidation (see Fig. 1c). It consists of a Ti-oxide (grey in BSE contrast) with embedded islands of oxides rich in Si (dark-grey in BSE contrast) (see Fig. 1a to c). At $1200{ }^{\circ} \mathrm{C}$ after $100 \mathrm{~h}$, a significantly thicker oxide scale (approximately $70 \mu \mathrm{m}$ in total) is observed. Two distinct sub-scales are identified: (i) a single-phase, top Ti-oxide scale and (ii) a duplex scale comprising Ti- and Si-oxide underneath (see Fig. 1d and e). The duplex oxide scale was found to comprise a considerable fraction of Si-oxide of $(52 \pm 6)$ vol\% [10]. The top Ti-oxide scale reveals a rather low porosity of (1.3 $\pm 0.2)$ vol\%. 

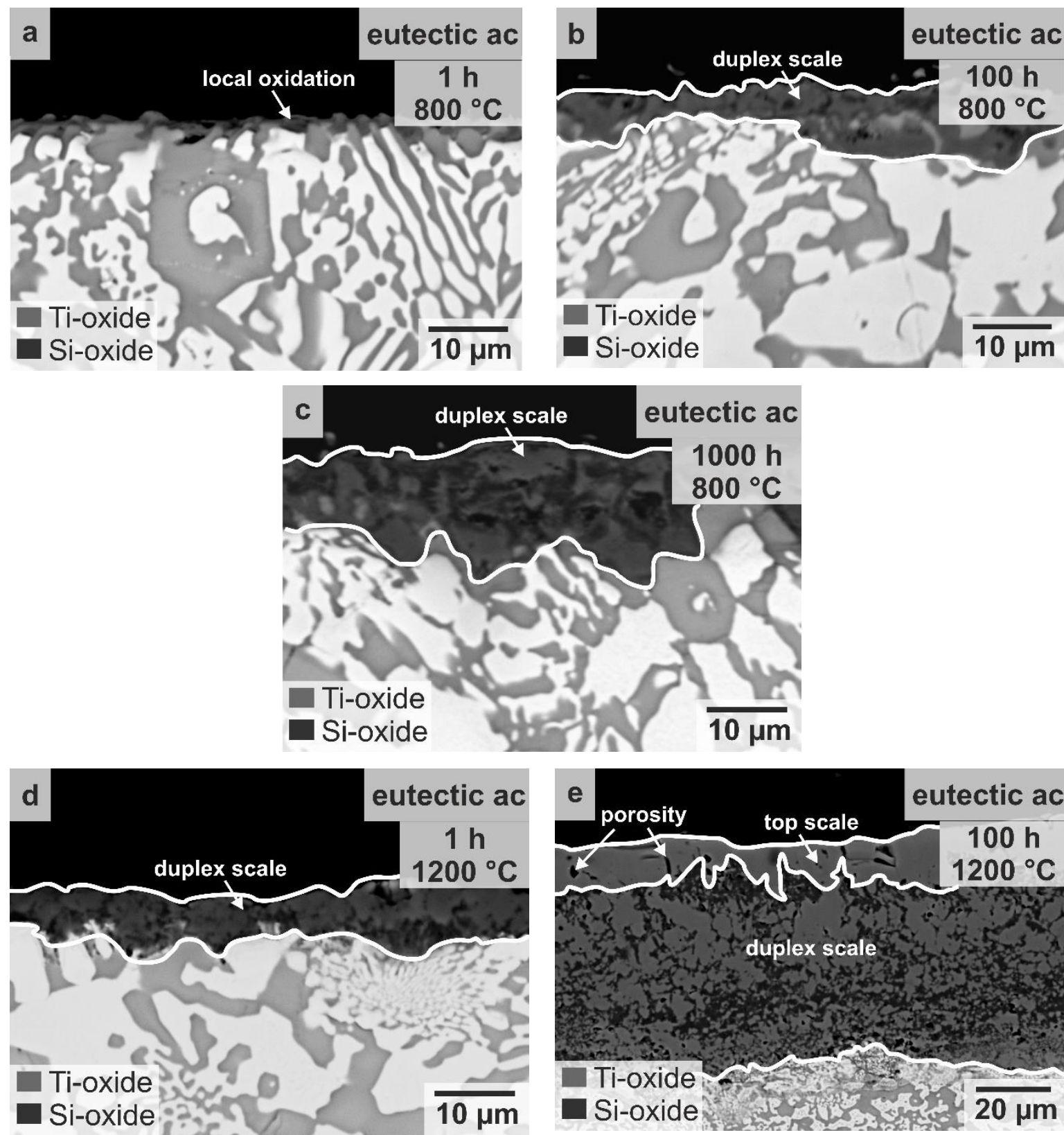

Fig. 1 BSE micrographs of the eutectic alloy Mo-20Si-52.8Ti after cyclic oxidation in laboratory air for 1, (a) 100 (b) and $1000 \mathrm{~h}(\mathrm{c})$ at $800{ }^{\circ} \mathrm{C}$ as well as 1 (d) and $100 \mathrm{~h}(\mathrm{e})$ at $1200{ }^{\circ} \mathrm{C}$. Dark grey is the Si-oxide, while the Ti-oxide is light grey.

149 GIXRD measurements at an incident angle of $\omega=1.2^{\circ}$, presented in Fig. 2, confirmed the oxide scales

150 formed at 800 and $1200^{\circ} \mathrm{C}$ to be mainly composed of rutile $\mathrm{TiO}_{2}, \mathrm{Ti}\left(+\mathrm{IV}\right.$ )-oxide (space group $\mathrm{P} 4_{2} / \mathrm{m} \mathrm{n}$

$151 \mathrm{~m}$ ) and small amounts of cristobalite $\mathrm{SiO}_{2}, \mathrm{Si}\left(+\mathrm{IV}\right.$ )-oxide (space group $\mathrm{P} 4_{1} 2_{1} 1$ ). Thus, with respect to the considerable volume fraction of the (dark-grey) Si-oxide within the Si-Ti-oxide duplex scale formed at $1200{ }^{\circ} \mathrm{C}$ (see Fig. 1e), it is expected that $\mathrm{SiO}_{2}$ is mostly amorphous. This is in good agreement with the results presented in Ref. [9] by electron back-scatter diffraction (EBSD). Besides, rutile $\mathrm{TiO}_{2}$, some peaks at $2 \Theta=26.78,42.82,63.04$ and $65.57^{\circ}$ can be assigned to ordered $\mathrm{TiO}$ (space group $\mathrm{C} 12 / \mathrm{m} 1$ ). While the peaks at $2 \Theta=42.82,63.04$ and $65.57^{\circ}$ are either superimposed by $(\mathrm{Ti}, \mathrm{Mo})_{5} \mathrm{Si}_{3}$ (in the case of the $800{ }^{\circ} \mathrm{C}$ oxidation sample), or cristobalite $\mathrm{SiO}_{2}$, the peak at $2 \Theta=26.78^{\circ}$ only matches the plane group 
158 (111) of ordered TiO. However, more characteristic peaks of ordered TiO, for instance at $2 \Theta=30.29$, 159 or $46.74^{\circ}$ of plane groups (111) and (021), respectively, would be expected, if a representative fraction 160 is prevalent in the oxide scale. Thus, the GIXRD results do not confirm the presence of TiO. 161 Additionally, some weak peaks at $2 \Theta=35.36,39.85$ and $69.90^{\circ}$ are assigned to the plane groups (410),

162 (501) and (621) of $\mathrm{MoO}_{3}$ (space group $\mathrm{P} \mathrm{b} \mathrm{n} \mathrm{m}$ ). Note that the peak at $2 \Theta=69.90^{\circ}$ is superimposed 163 by a rutile peak at $69.09^{\circ}$ at $1200{ }^{\circ} \mathrm{C}$. The detection of $\mathrm{MoO}_{3}$ is attributed to re-deposition of volatile $164 \mathrm{MoO}_{3}$ on the oxide surface and partial incorporation into the growing oxide scale. Additionally, the $165800{ }^{\circ} \mathrm{C}$ oxidation sample exhibits numerous peaks that can be assigned to ( $\left.\mathrm{Ti}, \mathrm{Mo}\right)_{5} \mathrm{Si}_{3}$. This is reasonable 166 as the oxide scale possesses a rather low thickness and sub-oxide regions of the substrate were likely 167 detected even by GIXRD. This is confirmed by additional measurements with increasing incident angles 168 and therefore increased information depth, as the respective peaks become more pronounced (see Supp. 1691 for GIXRD results with an increased incident angle of $\omega=2.5^{\circ}$ ). Furthermore, peaks corresponding 170 to bcc Moss are not detected, which is in good agreement with the observations made by SEM analysis 171 (see Fig. 1a and b), showing that surface-near Moss regions suffer from oxidation while the (Ti,Mo) ${ }_{5} \mathrm{Si}_{3}$ 172 regions remain almost unaffected. Moreover, there are two weak peaks at $2 \Theta=24.67$ and $31.32^{\circ}$ in the 173 GIXRD pattern of the $1200{ }^{\circ} \mathrm{C}$ oxidation sample, which cannot be assigned unambiguously. However, 174 these peaks neither correspond to the already discussed crystal structures, nor to further verified ones 175 (see Table 1).

Table 1 Examined crystal structures for evaluation of the GIXRD patterns (see Fig. 2).

\begin{tabular}{|c|c|c|c|}
\hline type & crystal structure & space group & $\begin{array}{l}\text { matching peaks with } \\
\text { GIXRD patterns }\end{array}$ \\
\hline \multirow{8}{*}{ Ti-oxides } & rutile $\mathrm{TiO}_{2}$ & $\mathrm{P} 42 / \mathrm{m} \mathrm{n} \mathrm{m}$ & yes \\
\hline & ordered TiO & $\mathrm{C} 12 / \mathrm{m} 1$ & $\begin{array}{l}\text { yes (superimposed by } \\
\text { peaks of other crystal } \\
\text { structures) }\end{array}$ \\
\hline & NaCl-type TiO & $\mathrm{Fm} \overline{3} \mathrm{~m}$ & - \\
\hline & monoclinic $\mathrm{Ti}_{3} \mathrm{O}_{5}$ & $\mathrm{C} 12 / \mathrm{m} 1$ & - \\
\hline & pseudobrookite $\mathrm{Ti}_{3} \mathrm{O}_{5}$ & $\mathrm{Cmcm}$ & - \\
\hline & corundum $\mathrm{Ti}_{2} \mathrm{O}_{3}$ & $\mathrm{R} \overline{3} \mathrm{c}$ & - \\
\hline & anatase $\mathrm{TiO}_{2}$ & $\mathrm{I} 4{ }_{1} / \mathrm{a} \mathrm{m} \mathrm{d}$ & - \\
\hline & brookite $\mathrm{TiO}_{2}$ & $\mathrm{Pbca}$ & - \\
\hline \multirow{2}{*}{ Si-oxides } & cristobalite $\mathrm{SiO}_{2}$ & $\mathrm{P} 4_{1} 2_{1} 1$ & yes \\
\hline & rutile $\mathrm{SiO}_{2}$ & $\mathrm{P} 4_{2} / \mathrm{m} \mathrm{n} \mathrm{m}$ & - \\
\hline \multirow{3}{*}{ Mo-oxides } & $\mathrm{MoO}_{3}$ & $\mathrm{Pbn} \mathrm{m}$ & yes \\
\hline & $\mathrm{VO}_{2}$-type $\mathrm{MoO}_{2}$ & P $12{ }_{1} / \mathrm{c} 1$ & - \\
\hline & rutile $\mathrm{MoO}_{2}$ & $\mathrm{P} 4_{2} / \mathrm{m} \mathrm{n} \mathrm{m}$ & - \\
\hline
\end{tabular}




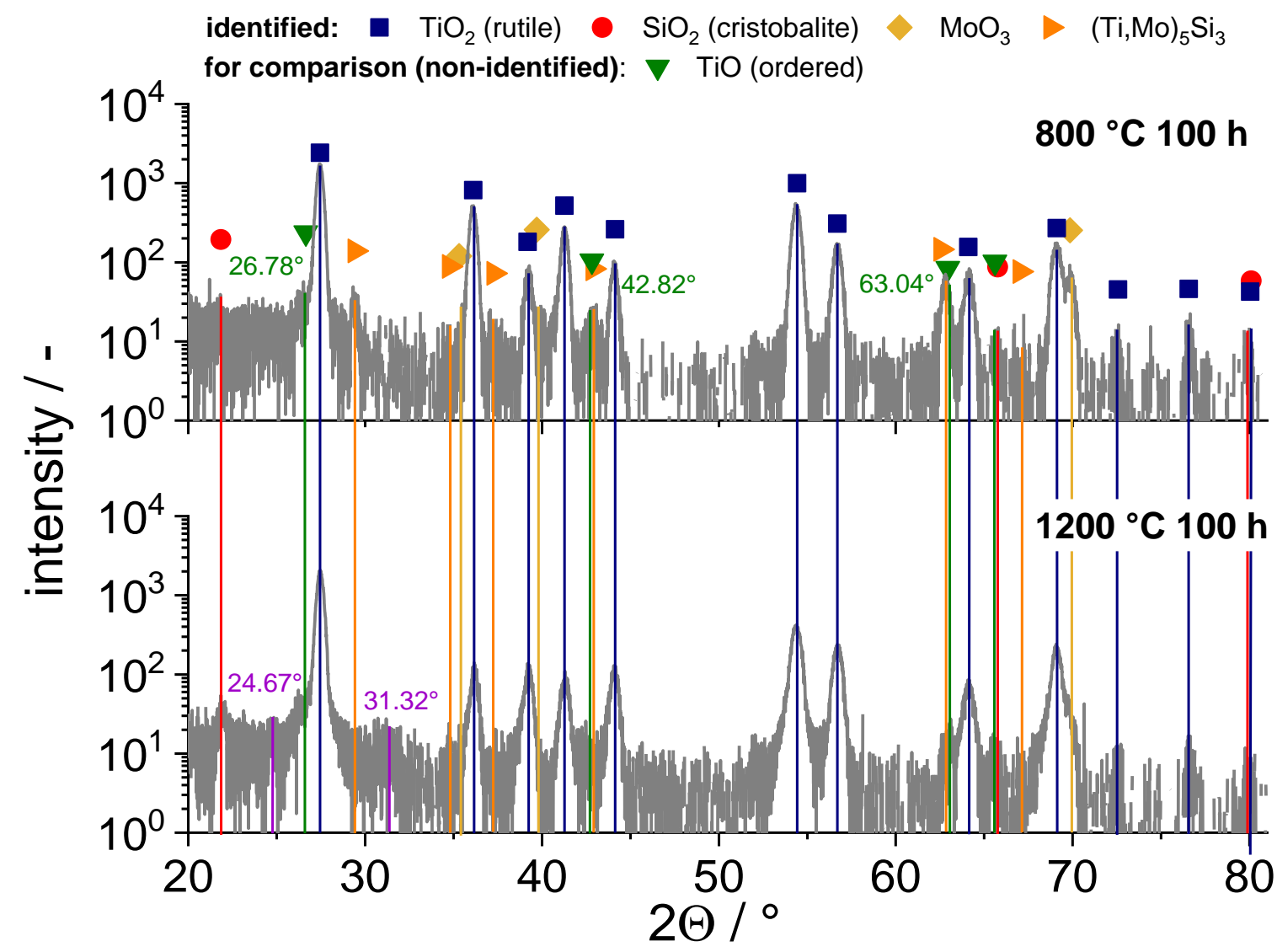

Fig. 2 GIXRD pattern of the surface of the oxidised sample at 800 (top) and $1200{ }^{\circ} \mathrm{C}$ (bottom) for 100 h. Note that the intensities are plotted in log scale. Diffraction angles that might correspond to ordered TiO (whose crystal structure cannot be identified unambiguously) are additionally labelled in green, whereas the non-assigned ones are labelled in violet colour.

\subsection{Chemical analysis of the oxide scales formed at 800 and $1200{ }^{\circ} \mathrm{C}$}

The mass spectra of the investigated atom probe tips are displayed in Fig. 3, showing the characteristic parts with the main peaks indicated. At $800{ }^{\circ} \mathrm{C}$, the Si-oxide tip could not be evaluated due to instabilities of tips manufactured from the oxide scale during APT analysis. Therefore, only the Ti-oxide tip was analysed (see Fig. 3a). For the $1200{ }^{\circ} \mathrm{C}$ sample, three regions of interest were evaluated (compare to BSE micrograph in Fig. 1e): (i) the top Ti-oxide scale (see Fig. 3b) and the underlying duplex scale of both, (ii) the Ti- and (iii) the Si-oxide region (see Fig. 3c and d).

The mass spectrum of the Ti-oxide region formed at $800{ }^{\circ} \mathrm{C}$ (Fig. 3a) mainly exhibits $\mathrm{TiO}$ and $\mathrm{TiO}_{2}$ as well as $\mathrm{O}$ ion-related peaks. Additionally, the spectrum contains the main peak of $\mathrm{Si}^{+}(28 \mathrm{Da}$ ) but no side peaks or other O-containing Si peaks are identified. Furthermore, no peaks related to Mo are present, which might have indicated the formation or incorporation of Mo-oxide. Thus, it can be concluded that the peak at $32 \mathrm{Da}$ predominantly results from $\mathrm{TiO}^{2+}$ ions. Nevertheless, the peak at $34 \mathrm{Da}$ (a side peak of $\mathrm{O}_{2}{ }^{+}$) indicates a significant contribution of $\mathrm{O}_{2}{ }^{+}$to the peak at $32 \mathrm{Da}$, which has to be taken into account for the determination of the chemical composition. After peak deconvolution the chemical composition 
was found to be 34.4 at $\% \mathrm{Ti}$ and 66.4 at $\% \mathrm{O}$ (see Table 2), confirming the presence of $\mathrm{TiO}_{2}$, $\mathrm{Ti}(+\mathrm{IV})$ oxide as already indicated by GIXRD analyses (see Fig. 2).

The mass spectrum of the top Ti-oxide region formed at $1200{ }^{\circ} \mathrm{C}$ (see Fig. 3b) exhibits similar peaks to the spectrum of the $800{ }^{\circ} \mathrm{C}$ sample, except the ones for $\mathrm{Al}^{+/ 2+}(27$ and $13.5 \mathrm{Da})$ and $\mathrm{AlO}^{2+}(21.5 \mathrm{Da})$. These peaks presumably result from a reaction with the alumina crucible during oxidation. The main peak of $\mathrm{Si}^{+}(28 \mathrm{Da})$ is identified as well and no Mo-related peaks are detected. Peak deconvolution reveals the chemical composition to be 31.7 at $\% \mathrm{Ti}$ and 68.3 at $\% \mathrm{O}$ in the top Ti-oxide, $1200{ }^{\circ} \mathrm{C}$ sample (see Table 2). Assuming no experimentally caused underestimate of the O content, (see Sect. 2), the presence of $\mathrm{TiO}_{2}, \mathrm{Ti}(+\mathrm{IV})$-oxide, is confirmed in the top layer by APT. This was also expected from the GIXRD analyses performed in this study (see Fig. 2) and from the EBSD results of the top Ti-oxide scale revealing rutile $\mathrm{TiO}_{2}$, see Ref. [9]. Although respective peaks are observed in the mass spectrum, the concentration of $\mathrm{Si}$ and $\mathrm{Al}$ is below 0.1 at $\%$.

The mass spectra of the Ti-oxide of the underlying duplex scale (see Fig. 3c) exhibits the same peaks found in the mass spectra of the top layer tips, including a small $\mathrm{Si}^{+}$peak at $28 \mathrm{Da}$. Again, no Mo peaks are observed and the duplex layer shows no peaks related to Al. The latter suggests that no reaction with the alumina crucible has occurred during oxidation testing. This is reasonable as the duplex scale is assumed to grow inwards and is separated from the atmosphere by the top Ti-oxide scale. Thus, it is not in contact with the crucible. In comparison to the top Ti-oxide, $1200{ }^{\circ} \mathrm{C}$ sample, a lower $\mathrm{O}$ content of only 59.0 at\% (equiv. to 41.0 at\% Ti) is determined after peak deconvolution. As discussed, it can be assumed that the APT analysis conditions did not cause an underestimation of the O content. EBSD analyses by Schliephake et al. [9] unambiguously confirmed the top oxide scale to be rutile $\mathrm{TiO}_{2}$, Ti(+IV)-oxide. However, in the underlying duplex scale, besides some rutile-assigned portions, multiple un-indexed regions were assumed to be amorphous $\mathrm{SiO}_{2}$. These un-assigned regions might represent another Ti-oxide than rutile $\mathrm{TiO}_{2}, \mathrm{Ti}(+\mathrm{IV})$-oxide.

The mass spectrum of the Si-oxide (see Fig. 3d) mainly exhibits peaks, which can be assigned to Si and $\mathrm{O}$ or combinations of both. Again, no Mo- or Al-related peaks are found. In contrast to all earlier discussed mass spectra, the peak at $32 \mathrm{Da}$ results predominantly from $\mathrm{O}_{2}{ }^{+}$ions. Small side peaks of $\mathrm{TiO}^{2+}$ ions can be observed at 31, 31.5, 32.5 and $33 \mathrm{Da}$. Using peak deconvolution, a total Ti content of about 0.4 at $\%$ is obtained for the Si-oxide. The concentrations of $\mathrm{Si}(38.0$ at $\%)$ and $\mathrm{O}(61.6$ at $\%)$ are close to the stoichiometry of $\mathrm{Si}(+\mathrm{IV})$-oxide $\mathrm{SiO}_{2}$, but this phase seems to be slightly depleted in $\mathrm{O}$, too, like the Ti-oxide in the duplex layer.

The corresponding subsets of the Ti-oxide, as well as of the Si-oxide regions within the duplex oxide scale, which were taken to determine the chemical composition of the phases, are included in Fig. 3e. The reconstructions of tip from the top Ti-oxide scales at 800 and $1200{ }^{\circ} \mathrm{C}$ are included in Supp. 2 for the sake of completeness. 


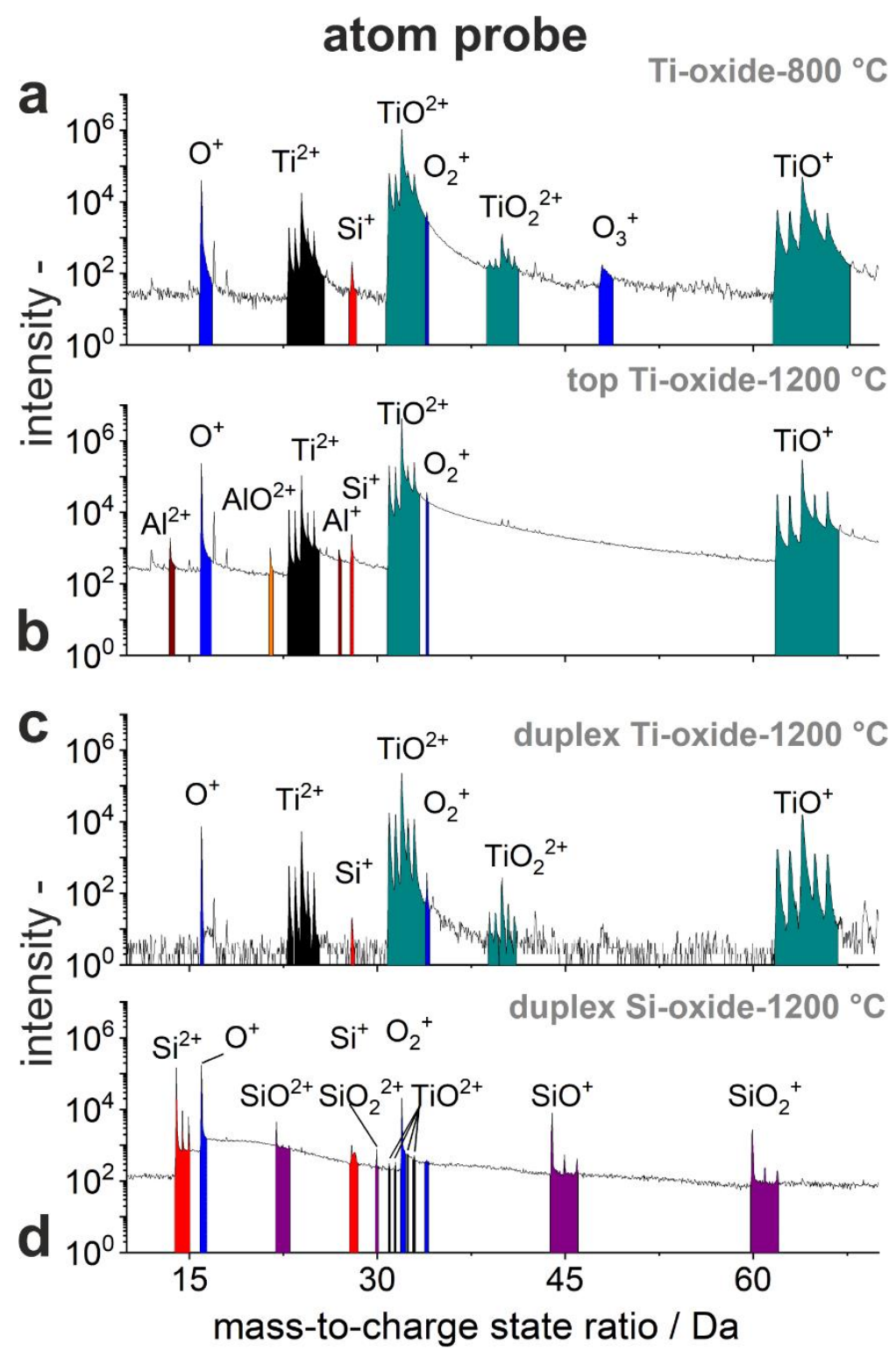

e

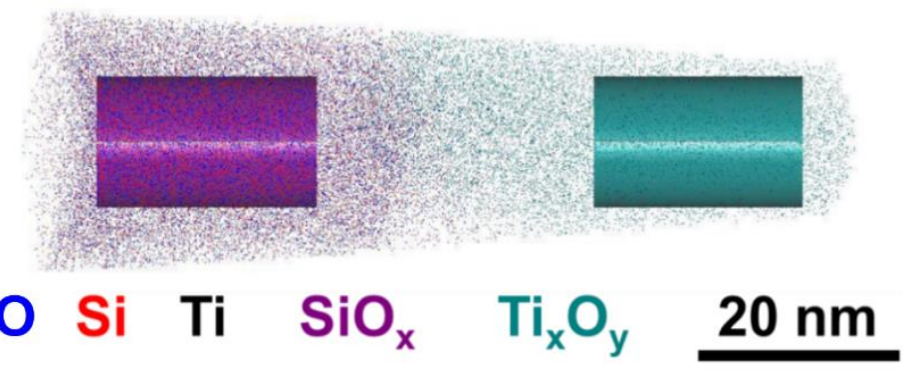

Fig. 3 Characteristic parts of the mass spectra of the top layer of the Ti-oxide- $800{ }^{\circ} \mathrm{C}$ sample (a), the top Ti-oxide-1200 ${ }^{\circ} \mathrm{C}$ sample (b), as well as the duplex Si-oxide-1200 ${ }^{\circ} \mathrm{C}(\mathrm{c})$ and the duplex Ti-oxide-1200 ${ }^{\circ} \mathrm{C}(\mathrm{d})$ regions of the duplex layer formed at $1200{ }^{\circ} \mathrm{C}$. Corresponding visualisation of the subsets for the analyses of the duplex oxide scale at $1200{ }^{\circ} \mathrm{C}(e)$, for reasons of clarity only $1 \%$ of all identified ions is shown here. 
Table 2 Chemical composition of the oxides in the investigated tips determined by APT after peak deconvolution (in at\%) and comparison to the predominant oxide stoichiometry. * In this case, several presumable oxide stoichiometries are compared based on the experimental results.

\begin{tabular}{|c|c|c|c|c|c|c|}
\hline / at\% & $\mathrm{Ti}$ & $\mathrm{Si}$ & $\mathrm{O}$ & $\mathrm{Al}$ & \multicolumn{2}{|c|}{ predominant oxide } \\
\hline Ti-oxide- $800{ }^{\circ} \mathrm{C}$ & 32.4 & $<0.1$ & 67.6 & - & $\mathrm{TiO}_{2.1}$ & $\mathrm{Ti}(+\mathrm{IV})$ \\
\hline top Ti-oxide-1200 ${ }^{\circ} \mathrm{C}$ & 31.7 & $<0.1$ & 68.3 & $<0.1$ & $\mathrm{TiO}_{2.2}$ & $\mathrm{Ti}(+\mathrm{IV})$ \\
\hline $\begin{array}{c}\text { duplex Ti-oxide- } \\
1200{ }^{\circ} \mathrm{C}^{*}\end{array}$ & 41.0 & $<0.1$ & 59.0 & - & $\mathrm{TiO}_{1.4}$ & $\mathrm{Ti}(+\mathrm{II})$ or Ti(+III) \\
& & & & & $\mathrm{Ti}_{2} \mathrm{O}_{2.9}$ & $\mathrm{Ti}(+\mathrm{III})$ \\
& & & & $\mathrm{Ti}_{3} \mathrm{O}_{4.3}$ & $\mathrm{Ti}(+\mathrm{IV} /+\mathrm{III})$ \\
\hline duplex Si-oxide-1200 ${ }^{\circ} \mathrm{C}$ & 0.4 & 38.0 & 61.6 & - & $\mathrm{SiO}_{1.6}$ & $\mathrm{Si}(+\mathrm{IV})$ \\
\hline
\end{tabular}

The experimental results of the Ti- and Si-oxide regions of the duplex scale are corroborated by literature data proving that $\mathrm{SiO}_{2}(\mathrm{Si}(+\mathrm{IV})$-oxide $)$ and $\mathrm{TiO}_{2}(\mathrm{Ti}(+\mathrm{IV})$-oxide) are in equilibrium at ambient pressure in air at 1100 [23] and $1200{ }^{\circ} \mathrm{C}$ [24], respectively. Moreover, there is only a solubility of 0.85 at\% $\mathrm{Si}$ in rutile $\mathrm{TiO}_{2}$ reported at $1300{ }^{\circ} \mathrm{C}$ for pressures of $3 \mathrm{GPa}$ and higher [25]. Assuming a linear dependence of solved $\mathrm{Si}$ in $\mathrm{TiO}_{2}$ with pressure, a solubility at ambient pressure of less than 0.57 at $\%$ can be extrapolated [25].

However, the unexpected stoichiometry and crystal structure of the Ti-oxide in the duplex scale at $1200{ }^{\circ} \mathrm{C}$ remains unsolved. As it is not clear what kind of oxidation level is prevalent in this oxide (see Table 2, third row), for instance $\mathrm{Ti}(+\mathrm{II}), \mathrm{Ti}(+\mathrm{III})$ or $\mathrm{Ti}(+\mathrm{IV})$, the oxide is designated as $\mathrm{Ti}_{x} \mathrm{O}_{y}$ with the general description of the oxidation level $\mathrm{Ti}(+2 y / x)$. This off-stoichiometric $\mathrm{Ti}_{x} \mathrm{O}_{y}$ is present as rutile $\mathrm{TiO}_{2}$ as confirmed by GIXRD in this work, because other crystal structure types cannot be assigned. Additionally, the presence of rutile was confirmed by EBSD in Ref. [9], whereas sub-surface regions are not indexed and might represent Ti-oxide other than rutile Ti(+IV)-oxide. However, the chemical composition determined by APT is not in agreement with the stoichiometry range of stable rutile $\mathrm{TiO}_{2}$ reported in literature ( $\mathrm{TiO}_{2-x}$ with $x=0$ to 0.04 [26, 27]). From a thermodynamic point of view, besides $\mathrm{TiO}_{2}$, the presence of $\mathrm{Ti}_{3} \mathrm{O}_{5}$ would be expected (solubility range $\mathrm{Ti}_{3} \mathrm{O}_{5+x}$ with $x=0$ to $0.1[26,28]$ ) as illustrated by the isothermal sections of the ternary Ti-Si-O (see Fig. 4a) and Mo-Si-O systems (see Fig. 4b) at the relevant temperatures of 1200 and 700 to $1000{ }^{\circ} \mathrm{C}$, respectively. The possibly formed oxidation products of the phases $\mathrm{Moss}_{\mathrm{SS}}$ and $\mathrm{Ti}_{5} \mathrm{Si}_{3}$ (when neglecting the influence of dissolved Mo of (11 \pm 3 ) at $\%$ (determined by $\mathrm{EDX}$ ) in $(\mathrm{Ti}, \mathrm{Mo})_{5} \mathrm{Si}_{3}$ ) can be seen when the $\mathrm{O}$ concentration (comparably to the oxygen partial pressure) is increased (dotted line). A stability region of $\mathrm{Ti}_{5} \mathrm{Si}_{3}, \mathrm{SiO}_{2}$ and $\mathrm{Ti}_{3} \mathrm{O}_{5}$ (highlighted in blue in Fig. 4a) can be reached when $\mathrm{Ti}_{5} \mathrm{Si}_{3}$ is significantly enriched with $\mathrm{O}$. With higher O concentration or increased oxygen partial pressure, $\mathrm{SiO}_{2}$ and $\mathrm{TiO}_{2}$ are in equilibrium with $\mathrm{O}$ (highlighted in green in Fig. 4a). $\mathrm{Ti}_{4} \mathrm{O}_{7}$ is here excluded, as it is not in equilibrium with $(\mathrm{Ti}, \mathrm{Mo})_{5} \mathrm{Si}_{3}$ and as the APT results do not match the stoichiometry. During oxidation of Moss the formation of $\mathrm{MoO}_{2}, \mathrm{SiO}_{2}$ and $\mathrm{MoO}_{3}$ occurs depending on the $\mathrm{O}$ concentration and oxygen partial pressure. Based on thermodynamics, it is likely that at the substrate surface $\mathrm{SiO}_{2}$ (solid) $+\mathrm{Ti}_{3} \mathrm{O}_{5}$ (solid) $+\mathrm{MoO}_{3}$ (volatile) are forming, while the 
composition of the duplex oxide scale of $\mathrm{SiO}_{2}+\mathrm{Ti}_{3} \mathrm{O}_{5}+\mathrm{MoO}_{3}$ (volatile) changes to $\mathrm{SiO}_{2}$ and $\mathrm{TiO}_{2}$ with increasing thickness. The presence of the top $\mathrm{TiO}_{2}$ oxide scale seems to be determined by the kinetics due to its observed fast-growing nature $[13,29]$ and the fast diffusion of $\mathrm{Ti}$ cations within $\mathrm{TiO}_{2}[30]$.
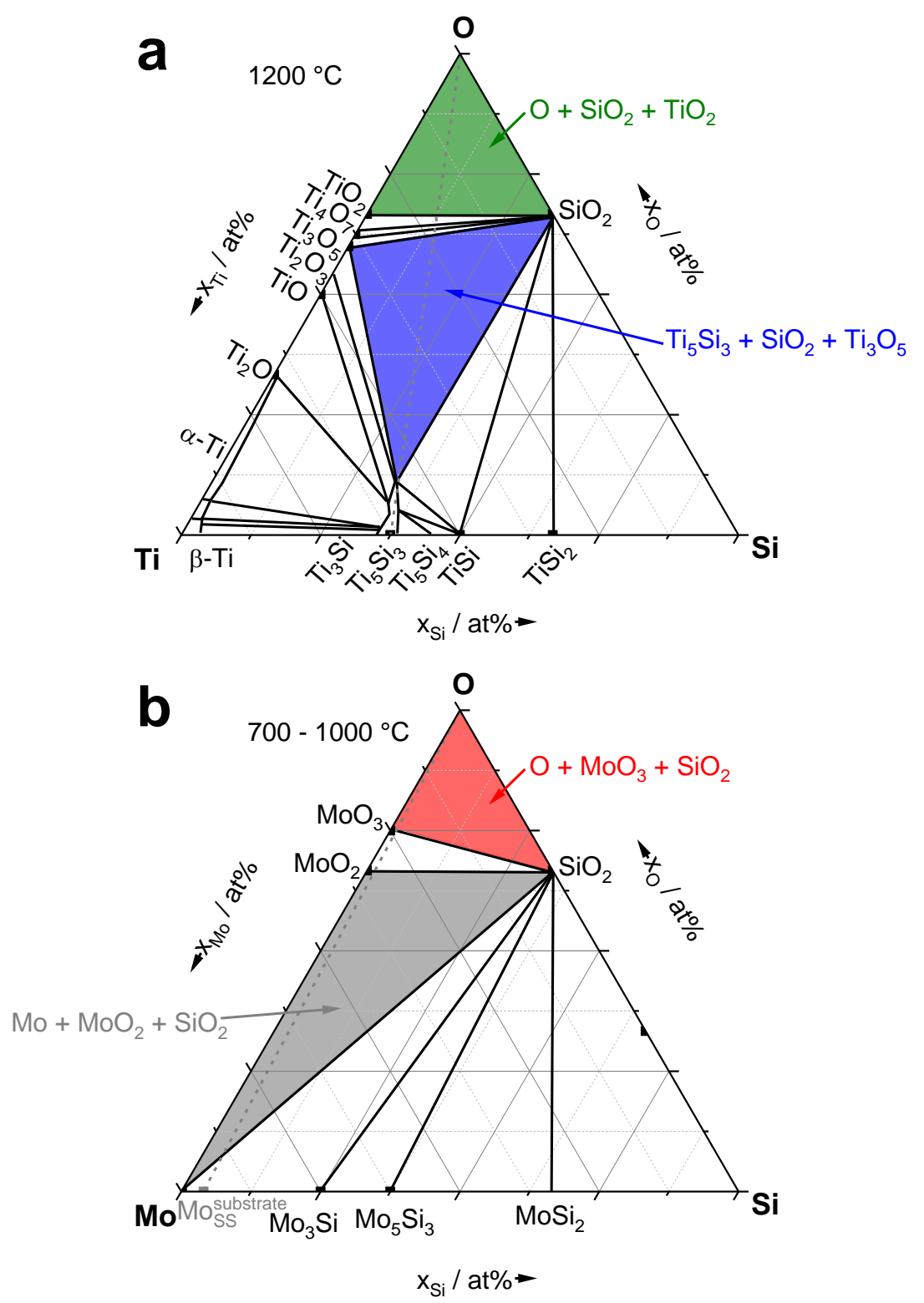

Fig. 4 Isothermal sections of the ternary Ti-Si-O (a) and Mo-Si-O (b) systems at 1200 and 700 to $1000{ }^{\circ} \mathrm{C}$, respectively, including selected, highlighted phase equilibria along the stability line of Tis $\mathrm{Si}_{3}$ or Moss (dotted grey line) with enrichment of $O[23,31]$.

\subsection{Analysis of the oxidation kinetics}

In the following, the oxidation kinetics will be referred to as the kinetics of oxide scale growth, if not otherwise stated. Literature data on weight change oxidation kinetics, which are considered for comparison, are explicitly highlighted.

257 The evolution of the (sub-)oxide scale thickness $d$ (internal oxidation $d_{\text {int }}$, duplex $d_{\text {duplex }}$ and top scale $d_{\text {top }}$ ) at $1200{ }^{\circ} \mathrm{C}$ is plotted in Fig. 5a as a function of time in double logarithmic manner (data at $100 \mathrm{~h}$ taken from our previous article [10]). The following power fit function for the oxide scale thickness $d$ 
in dependence of the exposure time $t$ with the oxidation rate constant $k_{n}$ for a specific exponent $n$ was applied:

$$
d^{n}=k_{n} \cdot t
$$

First, the fit was performed with the exponent $n$ being fixed to 2, which is equal to a parabolic oxide scale growth law [32]. Additionally, $n$ was adjusted individually in order to achieve optimum fit quality for comparison (dotted fit lines in Fig. 5a). It is revealed that: (i) The overall oxide scale growth at $1200{ }^{\circ} \mathrm{C}$ is dominated by the growth of the duplex scale (green circles). (ii) Both, the evolution of the oxide scale in total $d_{\text {total }}$ (violet triangles) and the duplex scale $d_{\text {duplex }}$ (green circles) are parabolic with $n$ values close to 2. (iii) Subtraction of the duplex scale data from the total oxide scale yields the change of the top single-phase oxide scale with time (blue triangles), which also seems to follow a parabolic rate law. However, a fit itself for the data points of the top single-phase was not possible since only two data points could be validly determined as for short oxidation times no separation of a top single-phase oxide scale was observed. In conclusion, the oxidation kinetics are determined to be parabolic and thus, the oxidation mechanism is regarded as bulk diffusion rate-controlled by either the oxidant (O anion) or the reactant (metal cation) through the (sub-)oxide scales.

In order to assess whether there is a change in oxidation mechanism with decreasing temperature and thus, less thermal activation for diffusion processes, the evolution of the total oxide scale thickness $d_{\text {total }}$ at $1200{ }^{\circ} \mathrm{C}$ is compared to the observations made at 800 and $1100{ }^{\circ} \mathrm{C}$ (see Fig. 5b). It is demonstrated that the oxide scales are considerably thicker at elevated temperatures, namely $(26 \pm 7)$ and $(68 \pm 11) \mu \mathrm{m}$ at 1100 and $1200{ }^{\circ} \mathrm{C}$, respectively, as compared to only $(5 \pm 2) \mu \mathrm{m}$ at $800{ }^{\circ} \mathrm{C}$ after $100 \mathrm{~h}$ of cyclic oxidation. Moreover, it is found that the oxide scale evolution might be associated with an almost cubic oxidation kinetics at $1100{ }^{\circ} \mathrm{C}$ as well, as revealed by an exponent of $n=2.94$ (see Table 3). The cubic and parabolic growth observed at 1100 and $1200{ }^{\circ} \mathrm{C}$, respectively, is attributed to diffusion processes, especially relevant at high temperatures. This is confirmed by the estimated diffusion distance of $\mathrm{Ti}^{4+}$ cations in $\mathrm{TiO}_{2}, \mathrm{Ti}(+\mathrm{IV})$-oxide at the respective temperatures, which is found to be 29 and $62 \mu \mathrm{m}$ after $100 \mathrm{~h}$ at 1100 and $1200{ }^{\circ} \mathrm{C}$, respectively, which is in excellent agreement to the experimental values. The impact of the temperature on the evolution of the oxide scale thickness is underlined by Fig. $5 \mathrm{c}$. The dependence of the total oxide scale thickness is highlighted as a function of temperature for specific exposure durations of 1,10 and $100 \mathrm{~h}$.

In contrast, the overall evaluation of the oxide scale growth at $800{ }^{\circ} \mathrm{C}$ does not yield parabolic kinetics, even after exposure times of $1000 \mathrm{~h}$, as a considerably increased exponent of $n=4.45$ according to Eq. 1 is noted. Such high exponents in power-law oxidation kinetics are neither widely reported, nor discussed in literature. Additionally, as only a moderate fit quality $\left(R_{a d j}^{2}=0.82\right)$ is obtained, it is suggested that there are different oxidation stages with changing oxidation kinetics. This suggestion is supported by considering the initial oxidation stage up to $100 \mathrm{~h}$ and the ongoing stage from 100 to $1000 \mathrm{~h}$ 
separately. During the initial oxidation stage, it is likely that the prevalent oxidation mechanism is reaction rate-controlled, as a linear fit leads to an excellent fit quality with $R_{a d j}^{2}=0.97$ (see Table 3). The obedience to linear oxidation kinetics is further corroborated by the discontinuous morphology of the oxide scale for exposure times shorter than $100 \mathrm{~h}$ (see BSE micrographs in Fig. 1). It is shown that the oxidation occurs locally, especially in the surface-near Moss regions, although not providing full coverage of the alloy substrate (see Fig. 1a and b). Therefore, the kinetics up to $100 \mathrm{~h}$ are most likely to be rate-determined by surface reactions occurring either at the oxide scale/atmosphere interface or at the oxide scale/substrate interface. Other oxidation mechanisms leading to linear oxidation kinetics, such as direct $\mathrm{O}$ access to the substrate through porous oxide scales or cracks, are unlikely, since neither significant porosity nor cracks are observed in the oxide scale by SEM analysis (see Fig. 1a and b). Note that this initial linear oxidation kinetics does not lead to catastrophic oxidation behaviour, as the oxidation rate constant of $8.25 \times 10^{-12} \mathrm{~ms}^{-1}$ is significantly low. For longer exposure times than $100 \mathrm{~h}$, a continuous mixed Si-Ti-oxide scale is formed (see Fig. 1c), which accounts for the change in oxidation kinetics. Fitting the respective values according to Eq. 1 leads to an exponent of 3.18 with a good fit quality of $R_{a d j}^{2}=0.94$. This reveals that the oxidation kinetics change from linear to cubic. In literature, cubic oxidation kinetics are assumed to be determined by diffusion processes along grain boundaries [33-35]. Thus, it might be that $\mathrm{O}$ inward diffusion along grain boundaries and Ti-oxide/Si-oxide phase boundaries determines the oxidation mechanism for exposure times longer than $100 \mathrm{~h}$. However, no profound evidence can be given here for this assumption.
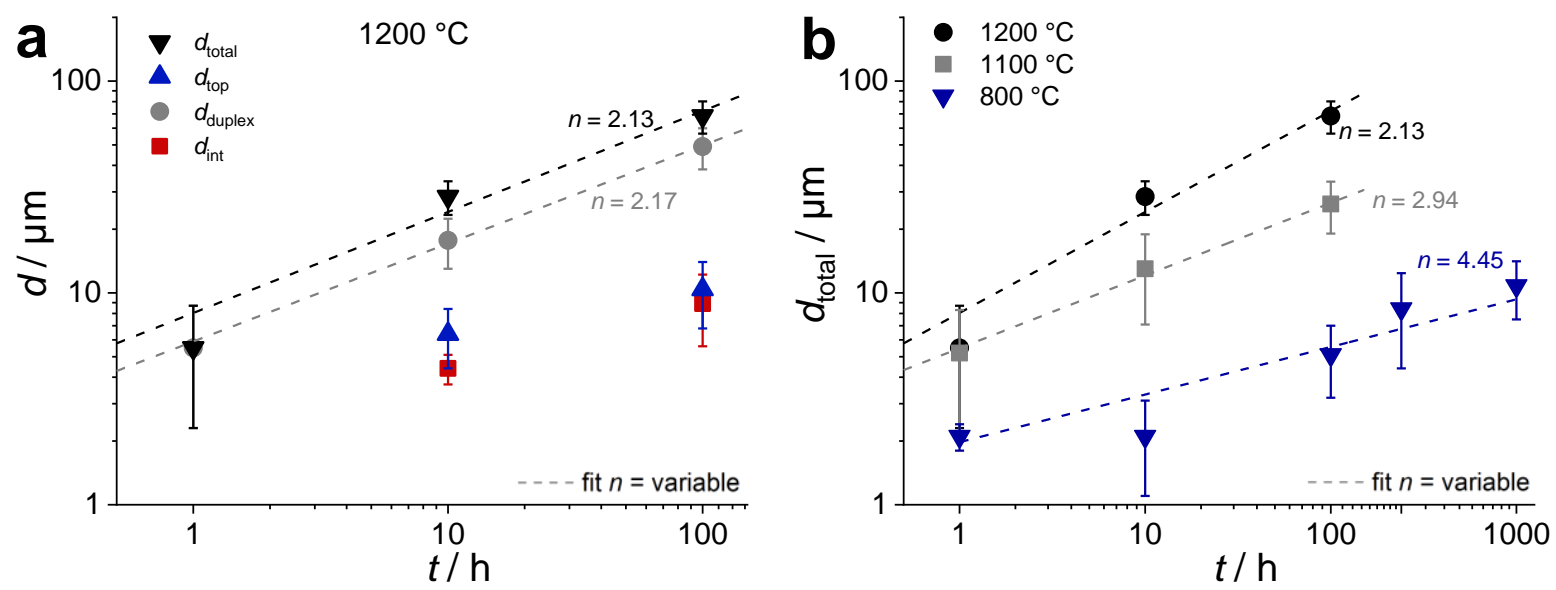


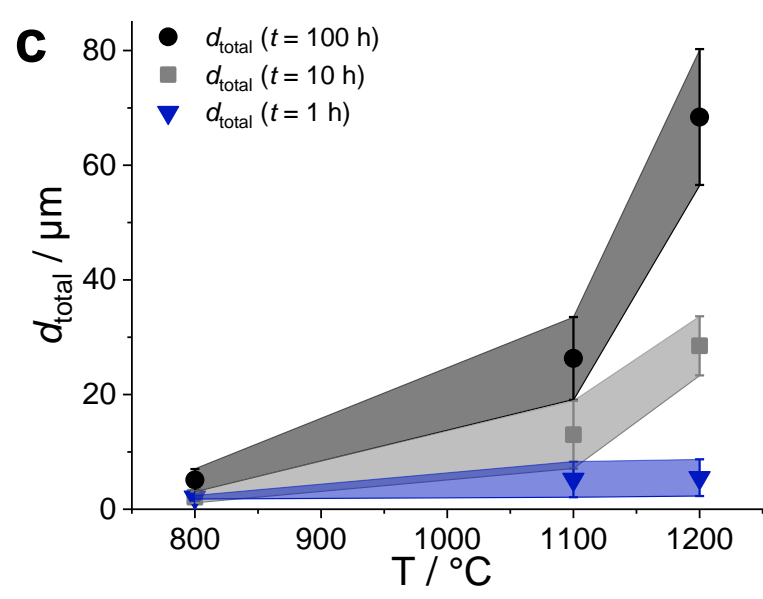

Fig. 5 Evolution of the oxide scale thickness in total $d_{\text {total }}$ and of the respective sub-scales (top Ti-oxide $d_{\text {top }}$, duplex Siand Ti-oxide scale $d_{\text {duplex }}$ and internal oxidation zone $d_{\text {int }}$ ) in dependence of the exposure time $t$ at $1200{ }^{\circ} \mathrm{C}$ for the eutectic alloy (a). Fit functions according to Eq. 1 with $n$ being adjusted variably (dotted lines) are included. In comparison $d_{\text {total }}$ is displayed logarithmically at 800,1100 and $1200{ }^{\circ} \mathrm{C}(b)$ and fitted accordingly as well $(b)$. The total oxide scale thicknesses are compared for different times at 800,1100 and $1200{ }^{\circ} \mathrm{C}(\mathrm{c})$.

Table 3 Determined oxidation rate constants $k_{n}$ for 800,1100 and $1200{ }^{\circ} \mathrm{C}$. For 1100 and $1200{ }^{\circ} \mathrm{C}$ referring to Eq. 1 . For $800{ }^{\circ} \mathrm{C} k^{*}$, referring to a linear fitting method, is included. $R_{\text {adj }}^{2}$ values are provided as well.

\begin{tabular}{|c|c|c|c|c|c|}
\hline \multirow{2}{*}{$\boldsymbol{T} /{ }^{\circ} \mathrm{C}$} & $\begin{array}{c}\text { fitting range } \\
\text { of } \boldsymbol{t} / \mathrm{h}\end{array}$ & $\boldsymbol{n} /-$ & $\boldsymbol{k}_{\boldsymbol{n}} / \mathrm{m}^{\mathrm{n}} \mathrm{s}^{-1}$ & $\boldsymbol{k}^{*} / \mathrm{ms}^{-1}$ & $\boldsymbol{R}_{\boldsymbol{a d j}}^{2} /-$ \\
\hline \multirow{3}{*}{800} & $1-1000$ & 4.45 & $1.16 \times 10^{-29}$ & - & 0.82 \\
\cline { 2 - 6 } & $1-100$ & 1 (linear) & - & $8.25 \times 10^{-12}$ & 0.97 \\
\cline { 2 - 6 } & $100-1000$ & 3.18 & $4.51 \times 10^{-23}$ & - & 0.94 \\
\cline { 2 - 6 } & $100-1000$ & 2 (parabolic) & $4.41 \times 10^{-17}$ & - & 0.61 \\
\hline \multirow{2}{*}{1100} & $1-100$ & 2.94 & $8.64 \times 10^{-20}$ & - & 0.99 \\
\cline { 2 - 6 } & \multirow{2}{*}{1200} & 2 (parabolic) & $2.38 \times 10^{-15}$ & - & 0.86 \\
\hline \multirow{2}{*}{} & $1-100$ & 2.13 & $3.56 \times 10^{-15}$ & - & 0.96 \\
\cline { 3 - 6 } & & 2 (parabolic) & $1.51 \times 10^{-14}$ & - & 0.96 \\
\hline
\end{tabular}

313 The high-temperature parabolic oxidation behaviour of the eutectic alloy Mo-20Si-52.8Ti is

314 characterised by the parabolic oxidation rate constant $k_{n=2}=2.38 \times 10^{-15}\left(1100{ }^{\circ} \mathrm{C}\right)$ to $1.51 \times 10^{-14} \mathrm{~m}^{2} \mathrm{~s}^{-1}$

$315\left(1200{ }^{\circ} \mathrm{C}\right)$, which are thermally activated with an activation energy of $310 \mathrm{~kJ} / \mathrm{mol}$. These findings also apply to certain eutectic-eutectoid alloys from Ref. [11] (see App. 1 for their chemical compositions), as well as to the eutectoid alloy from Ref. [9], as parabolic oxidation kinetics with similar oxidation rate constants to the eutectic alloy were revealed with activation energies in the range of 200 to $410 \mathrm{~kJ} / \mathrm{mol}$. Note that the determination of these activation energies is based on only two data points and thus, only serves as estimates when interpreting the activation energies.

Moreover, no difference was found between the pesting-resistant and non-pesting-resistant Ti-rich and Ti-lean (nominal Ti content < 43 at\%) alloys, respectively, which could have been taken into consideration for further understanding the root causes of pesting resistance. However, in order to 
classify the oxidation behaviour of these Mo-Si-Ti alloys, their parabolic oxidation rate constants $k_{n=2}$ are compared to the relevant diffusion coefficients of this systems. Since the oxidation rate constants are known to be thermally activated [36], these can be visualised by an Arrhenius plot in Fig. 6. The following correlation between the oxidation rate constant and the diffusion coefficient $D$ allows a direct comparison of the respective diagrams (see Eq. 2 [37]):

$$
k_{n=2}=\frac{2 D C_{0}}{N}
$$

Here, $D$ is the diffusion coefficient of a specific species diffusing in the oxide, $C_{0}$ is the oxidant concentration at the scale surface and $N$ is the number of oxidant species incorporated in the newly grown oxide of unit volume [37].

Generally, it is seen in Fig. 6 that Ti ion diffusion (solid blue line) is considerably faster than $\mathrm{O}$ ion diffusion in $\mathrm{TiO}_{2}$ (dotted, dashed and solid red lines). This is in good agreement with the assumption that the top Ti-rich oxide scale is growing outward by Ti-cation outward diffusion, which has also been experimentally verified by marker experiments by Azim et al. in Ref. [29] on Mo-Si-B-Ti alloys. In contrast, the diffusion coefficient for $\mathrm{Si}$ bulk diffusion in $\mathrm{SiO}_{2}$ is significantly lower compared to the diffusion coefficients for O. This is in accordance with the assessment of Deal and Grove in Ref. [38] who stated that $\mathrm{SiO}_{2}$ formation proceeds rather by the inward diffusion of $\mathrm{O}$, than by the outward diffusion of Si. Furthermore, the respective oxidation rate constants of the eutectic alloy $\left(k_{n=2}^{\text {eutectic }}\right)$, of the intermediate eutectic-eutectoid alloys ( $k_{n=2}^{\text {eutectic-eutectoid }}$ ) and of the eutectoid alloy $\left(k_{n=2}^{\text {eutectoid }}\right)$ are found to be in the range of the diffusion coefficient of $\mathrm{Ti}$ in $\mathrm{TiO}_{2}$. Hence, it can be concluded that the oxidation rate of these eutectic-eutectoid Mo-Si-Ti alloys is determined by the Ti diffusion in $\mathrm{TiO}_{2}$.

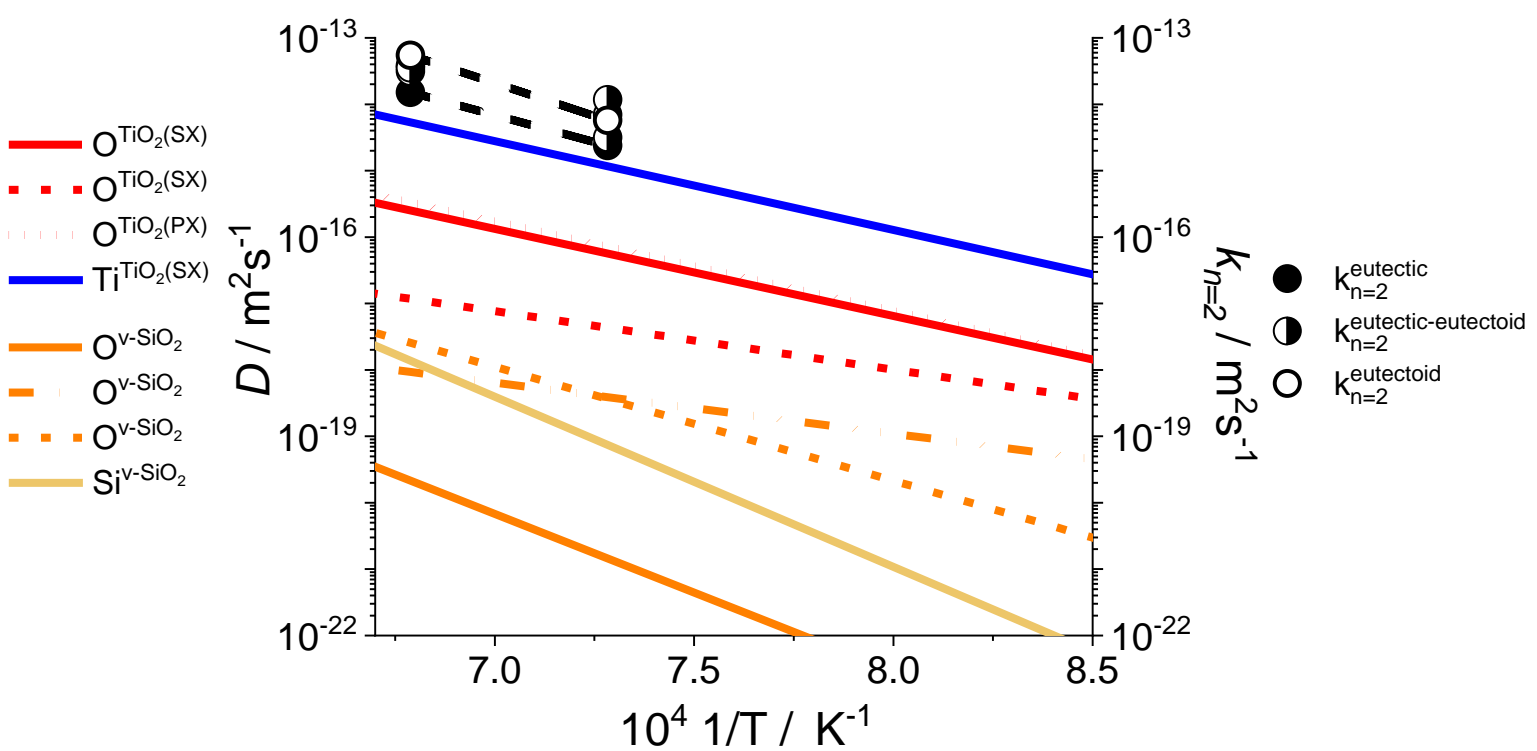

Fig. 6 Temperature-dependence of the diffusion coefficients D of Ti and O ions in single-crystalline (SX) and polycrystalline $(\mathrm{PX}) \mathrm{TiO}_{2}$ (blue and red lines) and $\mathrm{Si}$ - and $\mathrm{O}$ ions in vitreous (v) $\mathrm{SiO}_{2}$ (yellow and orange lines), respectively. Data taken from [39-44]. For comparative reasons, the values of $k_{n=2}$ for the eutectic (black solid circle), eutecticeutectoid (half-opened circles) alloys and the eutectoid alloy (open black circle) are added. 
In order to understand the observed oxidation kinetics in the Mo-Si-Ti system, the individual oxidation behaviour of the constitutional phases $\mathrm{Moss}_{\mathrm{ss}}$ and $(\mathrm{Ti}, \mathrm{Mo})_{5} \mathrm{Si}_{3}$ will be discussed in the following. Mo is known to undergo catastrophic oxidation due to volatilisation of $\mathrm{MoO}_{3}$ at temperatures above $500{ }^{\circ} \mathrm{C}$ [45-47]. The respective activation energy for temperatures beyond $800{ }^{\circ} \mathrm{C}$ was associated with a diffusion-controlled process through the gas phase [45, 47, 48] with $82 \mathrm{~kJ} / \mathrm{mol}$ [45]. However, the tendency of forming volatile $\mathrm{MoO}_{3}$ can be counterbalanced by the formation of solid Ti-rich oxides, when alloyed with $\mathrm{Ti}$ [11]. Thus, the linear mass loss oxidation rate can be considerably decelerated at $800{ }^{\circ} \mathrm{C}$, namely from -33 to $-14 \mathrm{mg} / \mathrm{cm}^{2} \mathrm{~h}^{-1}$, when increasing the Ti content from 20 to 40 at $\%$ [11]. The here discussed eutectic alloy comprises a Ti-rich Moss with an approximate Ti content of 45 at\% [10]. This supports the observed pesting-resistance in Ti-rich Mo-Si-Ti and Mo-Si-B-TiC alloys at $800{ }^{\circ} \mathrm{C}$ with considerable volume fractions of Ti-containing Moss $[10,11,49]$. Therefore, the improvement in oxidation behaviour is attributed to the formation of a (relatively) dense $\mathrm{TiO}_{2}$ oxide scale [49].

In comparison, the silicide phase $\mathrm{Ti}_{5} \mathrm{Si}_{3}$ reveals different weight change oxidation kinetics, which are dependent on the Si content and the oxidation duration [50]. The ( $\mathrm{Ti}, \mathrm{Mo})_{5} \mathrm{Si}_{3}$ phase present in the investigated eutectic alloy exhibits a constant $\mathrm{Si}$ ratio close to the ideal stoichiometry due to ingot metallurgical manufacturing. Furthermore, there is a considerable Mo concentration of (13 \pm 4$)$ at $\%$ [11]. Therefore, the phase composition is regarded to be comparable to the studies made by Majumdar et al. in Ref. [12] on an Mo-30Si-40Ti alloy, which comprises a (Ti,Mo) ${ }_{5} \mathrm{Si}_{3}$ matrix, but with an increased Mo content of 26 at $\%$. The oxidation behaviour was reported to obey parabolic weight gain and oxide scale growth kinetics in the temperature range of 900 up to $1300{ }^{\circ} \mathrm{C}$ [12]. Thereby, the formation of an outer $\mathrm{TiO}_{2}$ scale and an underlying $\mathrm{SiO}_{2}-\mathrm{TiO}_{2}$ duplex scale was observed [12] like for the investigated Mo-Si-Ti alloys from the present study (the eutectic alloy Mo-20Si-52.8Ti, as well as the other derivatives from the Mo-Si-Ti system listed in App. 1). The authors concluded that the formation of volatile $\mathrm{MoO}_{3}$ is suppressed in (Ti,Mo) ${ }_{5} \mathrm{Si}_{3}$ [12]. The parabolic oxidation rate constant was found to be about half an order of magnitude lower than in the eutectic alloy at $1200{ }^{\circ} \mathrm{C}$ in Ref. [12] (compare with Table 2). The corresponding activation energies were determined to be 72 and $325 \mathrm{~kJ} / \mathrm{mol}$ in the temperature range between 900 to $1200{ }^{\circ} \mathrm{C}$ and 1200 to $1300{ }^{\circ} \mathrm{C}$, respectively [12]. This first seems comparably low, but was interpreted by the authors on the basis of the activation energy for diffusion of oxygen in fused $\mathrm{SiO}_{2}$ which was regarded to be in the same order [12]. At higher temperatures instead, the activation energy is comparable to the activation energies found for the Mo-Si-Ti alloys in this study (see App. 1). The difference in activation energies was attributed to a change in microstructural set-up of the duplex oxide scale with an increased volume fraction of $\mathrm{TiO}_{2}$, which might lead to accelerated $\mathrm{O}$ inward diffusion [12]. Conclusively, (Ti, Mo) ${ }_{5} \mathrm{Si}_{3}$ exhibits a diffusion-controlled oxidation behaviour, which is mainly attributed to the inward diffusion of $\mathrm{O}$ through the $\mathrm{SiO}_{2}-\mathrm{TiO}_{2}$ duplex scale [12]. phases Moss and $(\mathrm{Ti}, \mathrm{Mo})_{5} \mathrm{Si}_{3}$. At high temperatures the diffusion processes are fast enough to form 
continuous, solid oxide scales, which can be accounted for the parabolic bulk diffusion-controlled oxidation, comparable to the oxidation kinetics of $(\mathrm{Ti}, \mathrm{Mo})_{5} \mathrm{Si}_{3}$. By contrast, the oxidation kinetics at $800{ }^{\circ} \mathrm{C}$ are different to the ones observed for the constituting phases Moss and ( $\left.\mathrm{Ti}, \mathrm{Mo}\right)_{5} \mathrm{Si}_{3}$, as the eutectic alloy reveals linear oxidation kinetics at the beginning, turning into cubic kinetics for oxidation times longer than $100 \mathrm{~h}$.

These fundamental differences might be rationalised as follows: Generally, the defect structure of the oxide determines the oxidation kinetics. In the case of rutile $\mathrm{TiO}_{2}$ the defect structure depends on temperature, oxygen partial pressure, the exact stoichiometry [51] and impurities [52]. At 1100 and $1200{ }^{\circ} \mathrm{C}$, the main defects are $\mathrm{O}$ vacancies and $\mathrm{Ti}$ cations of different valences $\left(\mathrm{Ti}^{3+}, \mathrm{Ti}^{4+}\right)$ [53]. While the first primarily contribute to the non-stoichiometry $[53,54]$, the latter are the defects dominating scale formation.

\subsection{The role of the Ti-oxide within the oxide scales formed on the eutectic alloy Mo-20Si-52.8Ti} The good oxidation resistance of the Ti-oxide formed on the eutectic alloy Mo-20Si-52.8Ti (see Fig. 1) in comparison to pure $\mathrm{Ti}$ is unexpected $[36,55]$. Therefore, possible explanations are discussed in the following: In essence, the oxidation resistance of $\mathrm{Ti}$ is improved by reducing its $\mathrm{O}$ solubility [55], e. g. by alloying with $\mathrm{Al}$ or $\mathrm{Si}[16,56]$. A reduction in oxidation rate is attained in Ti- $x \mathrm{Si}$ alloys with $x=0.4$ to 1.7 or 12.7 at $\%$ Si at 500 to 700 and $850{ }^{\circ} \mathrm{C}$, respectively $[16,56]$. Moreover, a parabolic oxidation behaviour is observed for Ti-Si alloys in contrast to a linear one, which is present in pure Ti [56]. When 3.3 at\% Si or less are added, Si was found to be homogenously distributed within the oxide scale, either solved as solid solution in rutile $\mathrm{TiO}_{2}$ or as embedded $\mathrm{SiO}_{2}$ islands with diameters of less than $1 \mu \mathrm{m}$ at $850{ }^{\circ} \mathrm{C}$ [56]. In contrast, higher additions up to 13 at $\%$ Si were found to be inhomogeneous distributed within the oxide scale and even led to cracking at the substrate/oxide interface [16]. Hence, the Si concentration presumably accounts for a transition in oxide scale morphology preventing pore formation and spallation, which typically occurs in $\mathrm{TiO}_{2}$ formed on pure $\mathrm{Ti}$ [56]. There are several impacts of $\mathrm{Si}$ on the oxidation behaviour of Ti-Si alloys proposed: (i) Si might retard the inward diffusion of $\mathrm{O}$ and therefore lead to a reduction in penetration depth [56], as interstitially solved $\mathrm{Si}$ ions might reduce the amount of available $\mathrm{O}$ vacancy sites decelerating the diffusion rate of $\mathrm{O}$ in rutile $\mathrm{TiO}_{2}$ [56]. (ii) $\mathrm{The}^{2}$ presence of $\mathrm{SiO}_{2}$ facilitates the formation of a denser, less porous oxide scale and prevents recrystallisation and stratification of $\mathrm{TiO}_{2}$ due to the change in stress relaxation processes within the oxide scale $[16,56]$. However, it is questionable whether the very low amount of $\mathrm{Si} / \mathrm{SiO}_{2}$ in $\mathrm{TiO}_{2} / \mathrm{Ti}$ oxide below 0.1 at $\%$ formed on the eutectic alloy (see Table 2 and Fig. 2) can be taken into account for a reduction in $\mathrm{O}$ vacancies due to preoccupation by $\mathrm{Si}$ ions. For comparison, in $\mathrm{Ti}-\mathrm{Nb}$ alloys, solution of $\mathrm{Nb}^{5+}$ ions was observed in rutile $\mathrm{TiO}_{2}$ leading to a significant deceleration of oxide scale growth at 900 and $1000{ }^{\circ} \mathrm{C}$ in static air [57]. Thereby, $\mathrm{Nb}^{5+}$ ions were found to substitute $\mathrm{Ti}^{4+}$ ions with an estimated ratio of less than $0.14 \%$ [57]. 
Although, $\mathrm{TiO}_{2}$ formed on $\mathrm{Ti}$ or Ti-based alloys often suffers from cracking [16, 55, 58-60], the oxide scales (especially the Ti-oxide) formed on the eutectic alloy are crack-free with very low porosity of less than 1.5 vol\% along the oxide scale substrate interface [11]. This indicates that a change in density and adherence of the oxide scales allow for the high oxidation resistance. The crack formation is often caused by the formation of sub-layers like TiN [16], but none were observed on the current eutectic alloy Mo-20Si-52.8Ti. Moreover, the mismatch of the CTE needs to be considered with regard to the oxide/substrate compatibility. For this purpose, CTE values are compared in Table 4. There is no considerable difference in CTE, no matter whether $\mathrm{TiO}_{2}$ is growing on $\mathrm{Ti}$ or on the eutectic alloy. However, especially at longer exposure times and higher temperatures, the relationship between the top $\mathrm{TiO}_{2}$, the duplex scale and the eutectic alloy substrate has to be taken into account. The CTE of thermally grown $\mathrm{SiO}_{2}$ is about one order of magnitude lower, so it is likely that the $\mathrm{SiO}_{2}$ portions balance the thermal expansion of $\mathrm{TiO}_{2}$ within the (duplex) oxide scale and suppress crack formation during cyclic oxidation testing.

Table 4 Comparison of the coefficients of thermal expansions (CTE) of $\mathrm{Ti}_{1} \mathrm{TiO}_{2}, \mathrm{SiO}_{2}$ and the eutectic alloy Mo-20Si-52.8Ti.

\begin{tabular}{|c|c|c|}
\hline & $\mathrm{CTE} / \mathrm{K}^{-1}$ & Refs. \\
\hline $\mathrm{Ti}$ & $10.5 \times 10^{-6}\left(20-700^{\circ} \mathrm{C}\right)$ & {$[61]$} \\
\hline $\mathrm{TiO}_{2}$ & $a$-axis: $8.1 \times 10^{-6}\left(276^{\circ} \mathrm{C}\right)$ & {$[62]$} \\
& $c$-axis: $10.6 \times 10^{-6}\left(276^{\circ} \mathrm{C}\right)$ & \\
\hline $\mathrm{SiO}_{2}$ & $5 \times 10^{-7}\left(\mathrm{RT}-300^{\circ} \mathrm{C}\right)$ & {$[63]$} \\
\hline eutectic alloy & $7.0-9.1 \times 10^{-6}\left(300-1200^{\circ} \mathrm{C}\right)$ & this study \\
\hline
\end{tabular}

In conclusion, the beneficial impact of the Ti-oxide on the oxidation behaviour is attributed to the interaction with the Si-oxide, which might lead to a reduction in available vacancies for $\mathrm{O}$ inward diffusion. Additionally, with regard to the diffusion of $\mathrm{O}, \mathrm{Si}$ and $\mathrm{Ti}$, the $\mathrm{O}$ concentration being available for the formation of the duplex oxide scale at $1200{ }^{\circ} \mathrm{C}$ is determined by the $\mathrm{O}$ ion diffusion flux through the top $\mathrm{TiO}_{2}$ oxide scale. Once the duplex scale is formed, $\mathrm{Ti}$ ion diffusion (which might be faster along the penetrating Ti-oxide regions through the oxide scale) to the top $\mathrm{TiO}_{2}$ scale is necessary for further growth of the top $\mathrm{TiO}_{2}$ oxide scale. Therefore, it is concluded that the fast formation of the top $\mathrm{TiO}_{2}$ scale is triggered by kinetics and that its growth is slowed down with ongoing formation of the underlying duplex scale.

\section{Summary and Conclusion}

The analysis of the microstructural constitution of the oxide scales formed on the eutectic Mo-20Si52.8Ti alloy at $800{ }^{\circ} \mathrm{C}$ revealed a single-layered mixed oxide scale comprising $\mathrm{Ti}$ - and $\mathrm{Si}$-oxide. At $1200{ }^{\circ} \mathrm{C}$, a top Ti-oxide scale with an underlying mixed duplex Ti- and Si-oxide scale is observed. Besides rutile $\mathrm{TiO}_{2}$ and some cristobalite $\mathrm{SiO}_{2}$, GIXRD analyses indicate the presence of some $\mathrm{MoO}_{3}$ in the oxide scale formed at $1200{ }^{\circ} \mathrm{C}$. However, the formation of $\mathrm{MoO}_{3}$ is outbalanced and 
overcompensated by solid oxide scale formation as documented by negligible mass changes even after test durations of $100 \mathrm{~h}$. The assessment of the compositional constitution of the oxide scales by APT leads to the following conclusions: (i) The chemical composition of the (top) Ti-oxide scales formed at 800 and $1200{ }^{\circ} \mathrm{C}$ is found to be comparable with a stoichiometry matching rutile-type $\mathrm{TiO}_{2} \mathrm{Ti}(+\mathrm{IV})$ oxide. (ii) The duplex scale formed at $1200{ }^{\circ} \mathrm{C}$ is composed of an O-depleted Ti-oxide region offstoichiometric to typical known Ti-oxide, among which $\mathrm{Ti}_{3} \mathrm{O}_{5}$ is the most likely one to be present. (iii) The $\mathrm{Si}$-oxide region within the duplex scale is depleted in $\mathrm{O}$ as well, with a stoichiometry of $\mathrm{SiO}_{1.6}$ closest to $\mathrm{SiO}_{2}$. It is unlikely that this observed depletion in $\mathrm{O}$ is caused by an underestimation caused by the measurement conditions. (iv) Virtually no solubility of Mo is found in the Ti- and Si-oxide, respectively, for both oxide scales formed at 800 and $1200{ }^{\circ} \mathrm{C}$. (v) There is a negligible amount of $\mathrm{Si}$ solved in the Ti-oxide formed at 800 and $1200{ }^{\circ} \mathrm{C}$.

The study of the oxide growth kinetics revealed that the oxide scale growth obeys a linear rate law at $800{ }^{\circ} \mathrm{C}$ up to $100 \mathrm{~h}$ pointing to a surface reaction-controlled oxidation. Longer exposure times facilitate the formation of a continuous mixed oxide scale, which results in cubic oxidation kinetics. In contrast, at 1100 and $1200{ }^{\circ} \mathrm{C}$ the thickness of the overall oxide scale and of the duplex scale grows with almost parabolic oxidation kinetics. This is also found for the eutectoid and eutectic-eutectoid Mo-Si-Ti alloys. The activation energies of the parabolic oxidation rate constants are in good agreement with published data on activation energies for self-diffusion of $\mathrm{O}$, $\mathrm{Ti}$ and $\mathrm{Si}$ in the respective oxides [39-44, 64] confirming the oxidation rate to be diffusion-controlled. The observed change in oxidation mechanism between 800 and $1100{ }^{\circ} \mathrm{C}$ correlates with the oxidation kinetics of the microstructural constituents Moss and (Ti,Mo) ${ }_{5} \mathrm{Si}_{3}$. While Moss is known to undergo catastrophic oxidation with linear mass loss [45, 46], which is decelerated with increasing Ti content [11], above $600{ }^{\circ} \mathrm{C},(\mathrm{Ti}, \mathrm{Mo})_{5} \mathrm{Si}_{3}$ was found to obey parabolic oxide growth kinetics in the temperature range of 900 to $1300{ }^{\circ} \mathrm{C}$ [12].

\section{Acknowledgements}

The authors gratefully acknowledge financial funding by Deutsche Forschungsgemeinschaft (DFG) within the framework of grant no. HE 1872/33-1. Additionally, thanks are due to our collaboration partners Matthias Weber, Bronislava Gorr and Hans-Jürgen Christ from the Institute for Materials Engineering, University of Siegen and Nadine Laska and Uwe Schulz from the Institute of Materials Research, German Aerospace Center (DLR). Many thanks are also given to Peter Mechnich from DLR for the support for measuring the CTE. This work was partly carried out with the support of the Karlsruhe Nano Micro Facility (KNMF, www.knmf.kit.edu), a Helmholtz Research Infrastructure at Karlsruhe Institute of Technology (KIT, www.kit.edu). 


\section{Appendix}

App. 1 Nominal chemical composition of eutectic-eutectoid Mo-Si-Ti alloys corresponding to Refs. [9, 11].

\begin{tabular}{|c|c|}
\hline eutectic-eutectoid alloys & nominal composition / at\% \\
\hline alloy \#1 & Mo-21Si-47Ti \\
\hline alloy \#2 & Mo-21Si-43.4Ti \\
\hline alloy \#3 & Mo-21.5Si-41.5Ti \\
\hline alloy \#4 & Mo-21Si34Ti \\
\hline
\end{tabular}

Supplementary

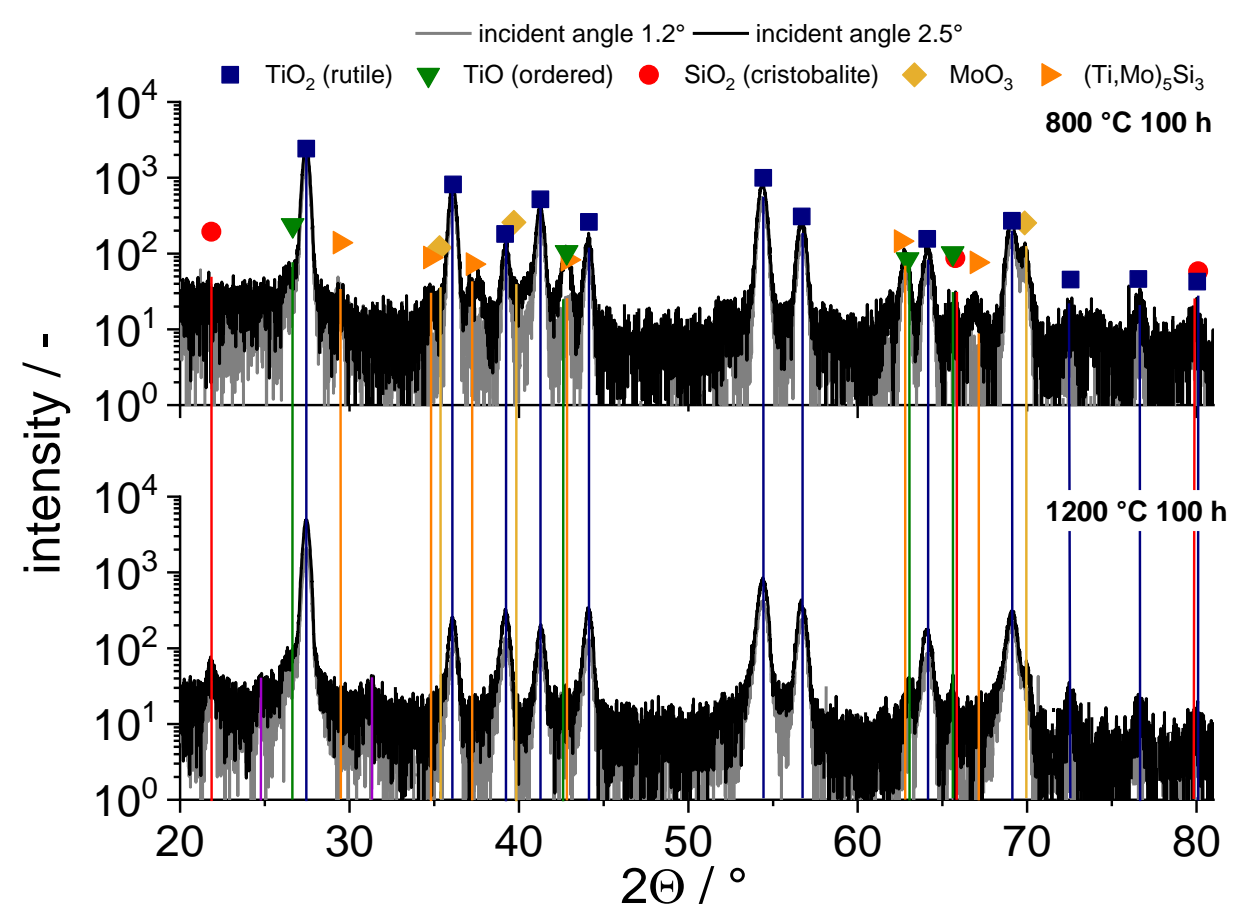

Supp. 1 GIXRD diffraction patterns of the cyclically oxidised samples at 800 (top) and $1200{ }^{\circ} \mathrm{C}$ (bottom) for $100 \mathrm{~h}$ with incident angles of 1.2 (grey) and $2.5^{\circ}$ (black). Note that the intensities are plotted with logarithmic scale. 


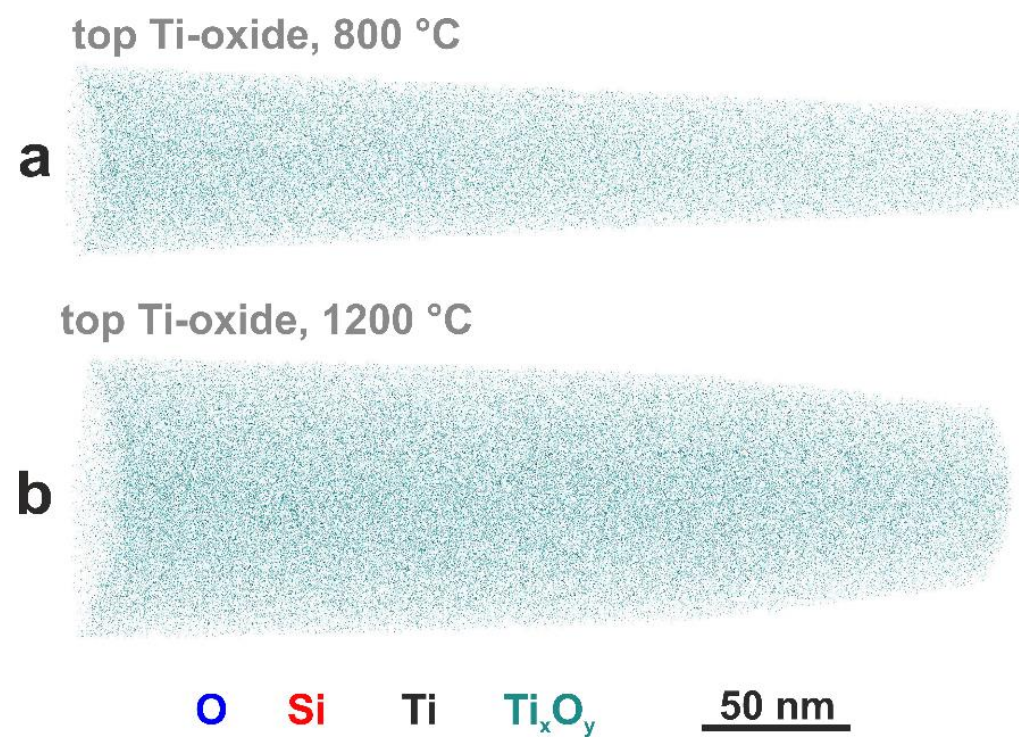

475

Supp. 2 Visualisation of the subsets for the APT analyses of the top Ti-oxide scale at $800(a)$ and $1200{ }^{\circ} \mathrm{C}(b)$. For reasons of clarity only $1 \%$ of all identified ions is shown here. No SiOx ions were identified.

\section{Data availability statement}

The raw and processed data required to reproduce these findings are available on request to alexander.kauffmann@kit.edu.

\section{References}

1. M. F. Yan, J. B. MacChesney, S. R. Nagel, W. W. Rhodes, Sintering of optical wave-guide glasses. Journal of Materials Science, 1980. 15(6): p. 1371-1378. DOI: 10.1007/BF00752116.

2. M. Meyer, M. Kramer, M. Akinc, Boron-doped molybdenum silicides. Advanced Materials, 1996. 8(1): p. 85-88. DOI: 10.1002/adma.19960080118.

3. M. K. Meyer, A. J. Thom, M. Akinc, Oxide scale formation and isothermal oxidation behavior of $\mathrm{Mo}-\mathrm{Si}-\mathrm{B}$ intermetallics at $600-1000^{\circ} \mathrm{C}$. Intermetallics, 1999. 7(2): p. 153-162. DOI: 10.1016/S0966-9795(98)00058-2.

4. K. Yoshimi, S. Nakatani, T. Suda, S. Hanada, H. Habazaki, Oxidation behavior of $\mathrm{Mo}_{5} \mathrm{SiB}_{2-}$ based alloy at elevated temperatures. Intermetallics, 2002. 10(5): p. 407-414. DOI: 10.1016/S0966-9795(02)00013-4.

5. Y. Yang, H. Bei, S. Chen, E. P. George, J. Tiley, Y. A. Chang, Effects of Ti, Zr, and Hf on the phase stability of $\mathrm{Moss}_{3}+\mathrm{Mo}_{3} \mathrm{Si}+\mathrm{Mo}_{5} \mathrm{SiB}_{2}$ alloys at $1600^{\circ} \mathrm{C}$. Acta Materialia, 2010. 58(2): p. 541-548. DOI: 10.1016/j.actamat.2009.09.032.

6. A. Rahmel, P. J. Spencer, Thermodynamic Aspects of TiAl and $\mathrm{TiSi}_{2}$ Oxidation: The Al-Ti-O and Si-Ti-O Phase Diagrams. Oxidation of Metals, 1991. 35(1-2): p. 53-68. DOI: 10.1007/BF00666500.

7. T. A. Parthasarathy, M. G. Mendiratta, D. M. Dimiduk, Oxidation mechanisms in Moreinforced $\mathrm{Mo}_{5} \mathrm{SiB}_{2}$ (T2)-Mo3 $\mathrm{Si}$ alloys. Acta Materialia, 2002. 50(7): p. 1857-1868. DOI: 10.1016/S1359-6454(02)00039-3.

8. S. Paswan, R. Mitra, S. K. Roy, Oxidation behaviour of the Mo-Si-B and Mo-Si-B-Al alloys in the temperature range of $700-1300^{\circ} \mathrm{C}$. Intermetallics, 2007. 15(9): p. 1217-1227. DOI: 10.1016/j.intermet.2007.02.012.

9. D. Schliephake, A. Kauffmann, X. Cong, C. Gombola, M. A. Azim, B. Gorr, H.-J. Christ, M. Heilmaier, Constitution, oxidation and creep of eutectic and eutectoid Mo-Si-Ti alloys. Intermetallics, 2019. 104: p. 133-142. DOI: 10.1016/j.intermet.2018.10.028.

10. S. Obert, A. Kauffmann, M. Heilmaier, Characterisation of the oxidation and creep behaviour of novel Mo-Si-Ti alloys. Acta Materialia, 2020. 184: p. 132-142. DOI: 10.1016/j.actamat.2019.11.045. 
11. S. Obert, A. Kauffmann, S. Seils, S. Schellert, M. Weber, B. Gorr, H.-J. Christ, M. Heilmaier, On the chemical and microstructural requirements for the pesting-resistance of Mo-Si-Ti alloys. JMR\&T, 2020. 9(4): p. 8556-8567. DOI: 10.1016/j.jmrt.2020.06.002.

12. S. Majumdar, P. K. Singh, A. K. Pandey, G. V. S. N. Rao, Kinetics of oxide scale growth on a (Ti,Mo ${ }_{5} \mathrm{Si}_{3}$ based oxidation resistant $\mathrm{Mo}-\mathrm{Ti}-\mathrm{Si}$ alloy at $900-1300^{\circ} \mathrm{C}$. High Temperature Materials and Processes, 2019. 38(2019): p. 533-540. DOI: 10.1515/htmp-2019-0056.

13. M. A. Azim, B. Gorr, H.-J. Christ, O. Lenchuk, K. Albe, D. Schliephake, M. Heilmaier, Effect of $\mathrm{Ti}$ content and nitrogen on the high-temperature oxidation behavior of $\left(\mathrm{Mo}, \mathrm{Ti}_{5} \mathrm{Si}_{3}\right.$. Intermetallics, 2017. 90: p. 103-112. DOI: 10.1016/j.intermet.2017.05.023.

14. J. Dai, J. Zhu, C. Chen, F. Weng, High temperature oxidation behavior and research status of modifications on improving high temperature oxidation resistance of titanium alloys and titanium aluminides: A review. Journal of Alloys and Compounds, 2016. 685: p. 784-798. DOI: 10.1016/j.jallcom.2016.06.212.

15. J. Unnam, R. N. Shenoy, R. K. Clark, Oxidation of commercial purity titanium. Oxidation of Metals, 1986. 26(3-4): p. 231-252. DOI: 10.1007/BF00659186.

16. D. Vojtěch, B. Bártová, T. Kubatík, High temperature oxidation of titanium-silicon alloys. Materials Science and Engineering: A, 2003. 361(1-2): p. 50-57. DOI: 10.1016/S09215093(03)00564-1.

17. M. Yoshihara, Y.-W. Kim, Oxidation behavior of gamma alloys designed for high temperature applications. Intermetallics, 2005. 13(9): p. 952-958. DOI: 10.1016/j.intermet.2004.12.007.

18. J. Angseryd, F. Liu, H.-O. Andrén, S. S. A. Gerstl, M. Thuvander, Quantitative APT analysis of Ti(C, N). Ultramicroscopy, 2011. 111(6): p. 609-614. DOI: 10.1016/j.ultramic.2011.01.031.

19. R. Kirchhofer, D. R. Diercks, B. P. Gorman, J. F. Ihlefeld, P. G. Kotula, C. T. Shelton, G. L. Brennecka, Quantifying Compositional Homogeneity in $\mathrm{Pb}(\mathrm{Zr}, \mathrm{Ti}) \mathrm{O}_{3}$ Using Atom Probe Tomography. Journal of the American Ceramic Society, 2014. 97(9): p. 2677-2697. DOI: 10.1111/jace.13135.

20. F. Liu, K. Stiller, Atom probe tomography of thermally grown oxide scale on FeCrAl. Ultramicroscopy, 2013. 132: p. 279-284. DOI: 10.1016/j.ultramic.2013.02.004.

21. F. Tang, B. Gault, S. P. Ringer, J. M. Cairney, Optimization of pulsed laser atom probe (PLAP) for the analysis of nanocomposite Ti-Si-N films. Ultramicroscopy, 2010. 110(7): p. 836-843. DOI: 10.1016/j.ultramic.2010.03.003.

22. T. Boll, M. Thuvander, S. Koch, J. N. Wagner, N. Nedfors, U. Jansson, K. Stiller, An APT investigation of an amorphous Cr-B-C thin film. Ultramicroscopy, 2015. 159: p. 217-222. DOI: 10.1016/j.ultramic.2015.01.001.

23. J. I. Goldstein, S. K. Choi, F. J. J. V. Loo, G. F. Bastin, R. Metselaar, Solid-state Reactions and Phase Relations in the Ti-Si-O System at 1373 K. Journal of the American Ceramic Society, 1995. 78(2): p. 313-322. DOI: 10.1111/j.1151-2916.1995.tb08802.x.

24. A. Abba, A. Galerie, M. Caillet, High-temperature oxidation of titanium silicide coatings on titanium. Oxidation of Metals, 1982. 17(1-2): p. 43-54. DOI: 10.1007/BF00606192.

25. A. Escudero, F. Langenhorst, Incorporation of $\mathrm{Si}$ into $\mathrm{TiO}_{2}$ phases at high pressure. American Mineralogist, 2012. 97(4): p. 524-531. DOI: 10.2138/am.2012.3941.

26. S. Andersson, B. Collén, U. Kuylenstierna, A. Magnéli, Phase analysis studies on the titaniumoxygen system. Acta Chemica Scandinavica, 1957. 11(10): p. 1641-1652.

27. P. G. Wahlbeck, P. W. Gilles, Reinvestigation of the Phase Diagram for the System TitaniumOxygen. Journal of the American Ceramic Society, 1966. 49(4): p. 180-183. DOI: 10.1111/j.1151-2916.1966.tb13229.x.

28. R. R. Merritt, B. G. Hyde, L. A. Bursill, D. K. Philp, The thermodynamics of the titanium + oxygen system: An isothermal gravimetric study of the composition range $\mathrm{Ti}_{3} \mathrm{O}_{5}$ to $\mathrm{TiO}_{2}$ at 1304 K. Philosophical Transactions of the Royal Society of London. Series A, Mathematical and Physical Sciences, 1973. 274(1245): p. 627-661. DOI: 10.1098/rsta.1973.0078.

29. M. A. Azim, S. Burk, B. Gorr, H.-J. Christ, D. Schliephake, M. Heilmaier, R. Bornemann, P. H. Bolívar, Effect of Ti (Macro-) Alloying on the High-Temperature Oxidation Behavior of Ternary Mo-Si-B Alloys at 820-1300 ${ }^{\circ}$ C. Oxidation of Metals, 2013. 80(3-4): p. 231-242. DOI: 10.1007/s11085-013-9375-1.

30. D. A. Venkatu, L. E. Poteat, Diffusion of titanium of single crystal rutile. Materials Science and Engineering, 1970. 5(5): p. 258-262. DOI: 10.1016/0025-5416(70)90014-5. 
31. R. Beyers, Thermodynamic considerations in refractory metal-silicon-oxygen systems. Journal of Applied Physics, 1984. 56(1): p. 147-152. DOI: 10.1063/1.333738.

32. G. B. Gibbs, Vacancy generation and the kinetics of oxidation. Philosophical Magazine, 1968. 18(156): p. 1175-1180. DOI: 10.1080/14786436808227748

33. Z. Liu, W. Gao, Y. He, Modeling of oxidation kinetics of $\mathrm{Y}$-doped $\mathrm{Fe}-\mathrm{Cr}-\mathrm{Al}$ alloys. Oxidation of Metals, 2000. 53(3-4): p. 341-350. DOI: 10.1023/A:1004545421739.

34. D. Naumenko, B. Gleeson, E. Wessel, L. Singheiser, W. J. Quadakkers, Correlation between the microstructure, growth mechanism, and growth kinetics of alumina scales on a FeCrAlY alloy. Metallurgical and Materials Transactions A, 2007. 38(12): p. 2974-2983. DOI: 10.1007/s11661-007-9342-z.

35. W. J. Quadakkers, Growth mechanisms of oxide scales on ODS alloys in the temperature range $1000-1100^{\circ} \mathrm{C}$. Materials and Corrosion, 1990. 41(12): p. 659-668. DOI: 10.1002/maco.19900411204.

36. P. Kofstad, Oxidation of Metals: Determination of Activation Energies. Nature, 1957. 179(4574): p. 1362-1363. DOI: 10.1038/1791362a0.

37. C.-J. Han, C. R. Helms, Parallel oxidation mechanism for Si oxidation in dry $\mathrm{O}_{2}$. Journal of The Electrochemical Society, 1987. 134(5): p. 1297.

38. B. E. Deal, A. S. Grove, General Relationship for the Thermal Oxidation of Silicon. Journal of Applied Physics, 1965. 36(12): p. 3770-3778. DOI: 10.1063/1.1713945.

39. M. Dechamps, P. Lehr, Sur l'oxydation du titane $\alpha$ en atmosphère d'oxygène: Rôle de la couche oxydée et mécanisme d'oxydation. Journal of the Less Common Metals, 1977. 56(2): p. 193207. DOI: 10.1016/0022-5088(77)90041-8.

40. J. C. Mikkelsen, Self-diffusivity of network oxygen in vitreous $\mathrm{SiO}_{2}$. Applied Physics Letters, 1984. 45(11): p. 1187-1189. DOI: 10.1063/1.95086.

41. D. K. Moore, D. J. Cherniak, E. B. Watson, Oxygen diffusion in rutile from 750 to 1000 degrees $\mathrm{C}$ and 0.1 to $1000 \mathrm{MPa}$. American Mineralogist, 1998. 83(7-8): p. 700-711. DOI: 10.2138/am1998-7-803.

42. J. Rodríguez-Viejo, F. Sibieude, M. T. Clavaguera-Mora, C. Monty, ${ }^{18} \mathrm{O}$ diffusion through amorphous $\mathrm{SiO}_{2}$ and cristobalite. Applied Physics Letters, 1993. 63(14): p. 1906-1908. DOI: 10.1063/1.110644.

43. E. W. Sucov, Diffusion of Oxygen in Vitreous Silica. Journal of the American Ceramic Society, 1963. 46(1): p. 14-20. DOI: 10.1111/j.1151-2916.1963.tb13763.x.

44. T. Takahashi, S. Fukatsu, K. M. Itoh, M. Uematsu, A. Fujiwara, H. Kageshima, Y. Takahashi, K. Shiraishi, Self-diffusion of $\mathrm{Si}$ in thermally grown $\mathrm{SiO}_{2}$ under equilibrium conditions. Journal of Applied Physics, 2003. 93(6): p. 3674-3676. DOI: 10.1063/1.1554487.

45. E. A. Gulbransen, K. F. Andrew, F. A. Brassart, Oxidation of Molybdenum $550^{\circ}$ to $1700^{\circ} \mathrm{C}$. Journal of the Electrochemical Society, 1963. 110(9): p. 952-959. DOI: 10.1149/1.2425918.

46. E. S. Jones, J. F. Mosher, R. Speiser, J. W. Spretnak, The Oxidation of Molybdenum. Corrosion, 1958. 14(1): p. 20-26. DOI: 10.5006/0010-9312-14.1.20.

47. M. Simnad, A. Spilners, Kinetics and Mechanism of the Oxidation of Molybdenum. JOM, 1955. 7(9): p. 1011-1016. DOI: 10.1007/BF03377603.

48. R. W. Bartlett, Molybdenum Oxidation Kinetics at High Temperatures. Journal of The Electrochemical Society, 1965. 112(7): p. 744-746.

49. T. Hatakeyama, S. Ida, N. Sekido, K. Yoshimi, Significant improvement of the oxidation resistance of MoSiBTiC-based multiphase alloys by Ti enrichment. Corrosion Science, 2020: p. 108937. DOI: $10.1016 /$ j.corsci.2020.108937.

50. Z. Tang, J. J. Williams, A. J. Thom, M. Akinc, High temperature oxidation behavior of $\mathrm{Ti}_{5} \mathrm{Si}_{3}-$ based intermetallics. Intermetallics, 2008. 16(9): p. 1118-1124. DOI: 10.1016/j.intermet.2008.06.013.

51. J. He, R. K. Behera, M. W. Finnis, X. Li, E. C. Dickey, S. R. Phillpot, S. B. Sinnott, Prediction of high-temperature point defect formation in $\mathrm{TiO}_{2}$ from combined ab initio and thermodynamic calculations. Acta Materialia, 2007. 55(13): p. 4325-4337. DOI: 10.1016/j.actamat.2007.04.005.

52. P. Kofstad, Note on the defect structure of rutile $\left(\mathrm{TiO}_{2}\right)$. Journal of the Less Common Metals, 1967. 13(6): p. 635-638. DOI: 10.1016/0022-5088(67)90111-7. 
53. P. Kofstad, Thermogravimetric studies of the defect structure of rutile $\left(\mathrm{TiO}_{2}\right)$. Journal of Physics and Chemistry of Solids, 1962. 23(11): p. 1579-1586. DOI: 10.1016/0022-3697(62)90240-8.

54. F. Millot, C. Picard, Oxygen self-diffusion in non-stoichiometric rutile $\mathrm{TiO}_{2-\mathrm{x}}$ at high temperature. Solid State Ionics, 1988. 28: p. 1344-1348. DOI: 10.1016/0167-2738(88)90384-0.

55. P. Kofstad, P. B. Anderson, O. J. Krudtaa, Oxidation of titanium in the temperature range 800$1200^{\circ}$ C. Journal of the Less Common Metals, 1961. 3(2): p. 89-97. DOI: 10.1016/00225088(61)90001-7.

56. A. M. Chaze, C. Coddet, Influence of silicon on the oxidation of titanium between 550 and $700^{\circ} \mathrm{C}$. Oxidation of metals, 1987. 27(1-2): p. 1-20. DOI: 10.1007/BF00656726.

57. M. Yoshihara, K. Miura, Effects of $\mathrm{Nb}$ addition on oxidation behavior of TiAl. Intermetallics, 1995. 3(5): p. 357-363. DOI: 10.1016/0966-9795(95)94254-C.

58. Z. Alam, D. K. Das, Effect of cracking in diffusion aluminide coatings on their cyclic oxidation performance on Ti-based IMI-834 alloy. Corrosion Science, 2009. 51(6): p. 1405-1412. DOI: 10.1016/j.corsci.2009.03.027.

59. A. Ashrafizadeh, F. Ashrafizadeh, Structural features and corrosion analysis of thermally oxidized titanium. Journal of Alloys and Compounds, 2009. 480(2): p. 849-852. DOI: 10.1016/j.jallcom.2009.02.079.

60. J. Stringer, Some observations on the kinetics of oxidation of titanium at high temperatures. Journal of the Less Common Metals, 1964. 6(3): p. 207-213. DOI: 10.1016/00225088(64)90100-6.

61. P. Hidnert, Thermal expansion of titanium. J. Res. Natl. Bur. Stand, 1943. 30(1934): p. 101105.

62. R. K. Kirby, Thermal expansion of rutile from 100 to 700 K. Journal of Research of the National Bureau of Standards. Section A, Physics and Chemistry, 1967. 71(5): p. 363-369. DOI: 10.6028/jres.071A.041.

63. I. Blech, U. Cohen, Effects of humidity on stress in thin silicon dioxide films. Journal of applied physics, 1982. 53(6): p. 4202-4207. DOI: 10.1063/1.331244.

64. P. F. Dennis, R. Freer, Oxygen self-diffusion in rutile under hydrothermal conditions. Journal of Materials Science, 1993. 28(17): p. 4804-4810. DOI: 10.1007/BF00414275. 